OPEN ACCESS

Edited by:

Guido Lingua,

Università degli Studi del Piemonte

Orientale, Italy

Reviewed by:

Katarzyna Turnau,

Jagiellonian University, Poland

Roger Tai Koide,

Brigham Young University,

United States

*Correspondence:

Manuela Giovannett

manuela.giovannetti@unipi.it

Specialty section:

This article was submitted to

Plant Microbe Interactions,

a section of the journal

Frontiers in Plant Science

Received: 22 May 2018

Accepted: 05 July 2018

Published: 14 August 2018

Citation:

Avio L, Turrini A, Giovannetti $M$ and Sbrana C (2018) Designing the Ideotype Mycorrhizal Symbionts for the Production of Healthy Food.

Front. Plant Sci. 9:1089.

doi: $10.3389 /$ fpls.2018.01089

\section{Designing the Ideotype Mycorrhizal Symbionts for the Production of Healthy Food}

\author{
Luciano Avio ${ }^{1}$, Alessandra Turrini ${ }^{1,2}$, Manuela Giovannetti ${ }^{1,2 *}$ and Cristiana Sbrana ${ }^{3}$ \\ ${ }^{1}$ Department of Agriculture, Food and Environment, University of Pisa, Pisa, Italy, ${ }^{2}$ Interdepartmental Research Center \\ "Nutraceuticals and Food for Health", University of Pisa, Pisa, Italy, ${ }^{3}$ Institute of Agricultural Biology and Biotechnology, \\ C.N.R., UOS Pisa, Pisa, Italy
}

The new paradigm in agriculture, sustainable intensification, is focusing back onto beneficial soil microorganisms, for the role played in reducing the input of chemical fertilizers and pesticides and improving plant nutrition and health. Worldwide, more and more attention is deserved to arbuscular mycorrhizal fungi (AMF), which establish symbioses with the roots of most land plants and facilitate plant nutrient uptake, by means of a large network of extraradical hyphae spreading from colonized roots to the surrounding soil and functioning as a supplementary absorbing system. AMF protect plants from biotic and abiotic stresses and are able to modulate the activity of antioxidant enzymes and the biosynthesis of secondary metabolites (phytochemicals), such as polyphenols, anthocyanins, phytoestrogens and carotenoids, that play a fundamental role in promoting human health. An increasing number of studies focused on the use of AMF symbionts for the production of functional food, with enhanced nutritional and nutraceutical value. Yet, while several plant species were investigated, only few AMF were utilized, thus limiting the full exploitation of their wide physiological and genetic diversity. Here, we will focus on AMF effects on the biosynthesis of plant secondary metabolites with health-promoting activity, and on the criteria for a finely tuned, targeted selection of the best performing symbionts, to be utilized as sustainable biotechnological tools for the production of safe and healthy plant foods.

Keywords: arbuscular mycorrhizal symbionts, healthy food, nutraceutical value, sustainable agriculture, secondary metabolism gene regulation, AMF functional diversity, health-promoting phytochemicals

\section{INTRODUCTION}

The new paradigm in agriculture, sustainable intensification, is focusing back onto beneficial soil microorganisms, for the role played in reducing the input of chemical fertilizers and pesticides, while improving plant nutrition and health (Philippot et al., 2013). Worldwide, more and more attention is deserved to arbuscular mycorrhizal (AM) fungi (AMF), a key functional group of beneficial soil microbes belonging to the subphylum Glomeromycotina (Spatafora et al., 2016), able to establish a mutualistic symbiosis with the roots of $80 \%$ of plant species (Smith and Read, 2008). These encompass the most important crops for human consumption, such as wheat, rice, corn, barley, pulses, oats and millet, grapevine, olive, vegetables like strawberries, potato, tomato, medicinal plants and economically important species, such as sunflower, sugarcane, cotton, tobacco, coffee, tea, cocoa, rubber and cassava. AMF do not show host specificity, but are asexual obligate biotrophs, unable to complete their life cycle without host plants. 
AMF life cycle is simple: germinating spores originate a short-lived mycelium able to recognize the roots of host plants and to differentiate appressoria on their surface. Then appressoria produce hyphae growing intercellularly in the roots and arbuscules, a sort of haustoria formed within root cells, where nutrient exchanges between the two symbionts occur. Up to $20 \%$ of total plant photosynthates is transferred to AMF, which, as chemoheterotrophs, utilize them as carbon source (Jakobsen et al., 1992; Smith and Read, 2008; Giovannetti et al., 2012); such transfer enables AMF to grow and form new spores. On the other hand, the extensive extraradical mycelium (ERM) explores the surrounding soil beyond the depletion zone around roots, and increases the root absorbing surface (up to 40 times) (Giovannetti et al., 2001). ERM is able to uptake and translocate soil mineral nutrients, such as phosphorus $(\mathrm{P})$, nitrogen $(\mathrm{N})$, sulfur, potassium, calcium, iron, copper, and zinc, thus improving plant growth and biomass production (Lehmann and Rillig, 2015). In addition, AMF provide diverse ecosystem services, enhancing water uptake, and increasing plant tolerance to biotic and abiotic stresses (Gianinazzi et al., 2010), thereby decreasing the need of chemical fertilizers and pesticides inputs (Toussaint et al., 2008; Sikes et al., 2009).

Several studies reported that AMF may modulate the synthesis of secondary metabolites in host plants, leading to a higher activity of antioxidant enzymes and enhancing the levels of diverse phytochemicals with health-promoting activities (Sbrana et al., 2014). Such findings are very important, as worldwide both consumers and producers are increasingly interested in the health-promoting properties of plant-derived foods. Indeed a number of epidemiological studies reported the role played by some plant secondary metabolites, including polyphenols, glucosinolates, flavonoids and carotenoids in the prevention of chronic diseases, arteriosclerosis, heart diseases and cancer (Duthie, 2000; Johnson, 2002; Lund, 2003). For example, theaflavins and thearubigins from black teas showed antiproliferative action (Bhattacharya et al., 2009), grape seed extract exerted preventive effects against human colon carcinoma and lung epithelial cancer (Wang et al., 2007; Lazzè et al., 2009), luteolin, kaempherol, apigenin and myricetin from diverse fruits and vegetables possessed anti-inflammatory and antibacterial activities (Dillard and German, 2000) and essential oils from myrtle displayed antimutagenic and antigenotoxic properties (Mimica-Dukić et al., 2010). In addition, glucosinolates from broccoli, cauliflower and cabbage were able to modulate carcinogens metabolism and detoxification (Dillard and German, 2000; Tang et al., 2010), while allicin and its organosulfur derivatives from garlic showed antitumoral activities in diverse human cancers (Butt et al., 2009; Teiten et al., 2013; Zhang et al., 2015). Although such phytochemicals are expressed mainly depending on plant genotype, their production may be modulated by diverse agronomic and environmental factors, including AMF symbioses. Here, we will focus on AMF ability to modulate the biosynthesis of plant secondary metabolites with health-promoting activity, and on the criteria for a finely tuned, targeted selection of the best performing symbionts, to be utilized as sustainable biotechnological tools for the production of safe and healthy plant foods.

\section{THE PRODUCTION OF PHYTOCHEMICALS BY MYCORRHIZAL PLANTS}

A large body of evidence showed that the establishment of AM symbiosis induces changes in plant physiology, modulating the activity of host cell primary and secondary metabolism (Fester and Hause, 2005; Lohse et al., 2005; Schliemann et al., 2008; Wipf et al., 2014; Schweiger and Müller, 2015; Cervantes-Gámez et al., 2016). Many authors investigated the changes induced by AMF in secondary metabolism, in relation to the production of functional compounds in roots, shoots, leaves, fruits and seeds of many different plant species (Sbrana et al., 2014).

Mycorrhizal plants produced higher amounts of phytochemicals with therapeutic value, such as the phytoestrogens biochanin A, formononetin, genistein, daidzein, showing a preventive action in osteoporosis, menopausal symptoms and degenerative diseases (Ososki and Kennelly, 2003; Khaosaad et al., 2008), sesquiterpene lactones, able to inhibit cell proliferation and tumor growth (Jurkiewicz et al., 2010; Teiten et al., 2013), the cardioactive and hypotensive alkaloid forskolin (Sailo and Bagyaraj, 2005), furanocoumarins (angelicin and psoralen) and the chemotherapeutic agents pterocarpans (erybraedin C and bitucarpin A), able to induce apoptosis in human colon carcinoma cell lines (Maurich et al., 2006; Pistelli et al., 2017).

Different species of medicinal and aromatic plants were investigated for their phytochemical contents upon mycorrhizal colonization, showing higher shoot levels of antioxidant compounds, such as rosmarinic acid, caffeic acid and essential oils in basil (Copetta et al., 2006, 2007; Toussaint et al., 2008; Rasouli-Sadaghiani et al., 2010), and anthraquinone derivatives, such as hypericin and pseudohypericin in Hypericum perforatum (Zubek et al., 2012). Also the levels of essential oils showed altered profiles in mycorrhizal Origanum sp. (Karagiannidis et al., 2011), and large increases in the fruits of mycorrhizal Coriandrum sativum, Anethum graveolens, Trachyspermum ammi, in the leaves of Artemisia annua and in the seeds of Foeniculum vulgare (Kapoor et al., 2002a,b; Chaudhary et al., 2008). Moreover, mycorrhizal plants of Stevia rebaudiana showed enhanced levels of the health-promoting compounds steviol glycosides (Tavarini et al., 2018).

Apart from medicinal plants and herbs, works investigating the phytochemical content of mycorrhizal plants cultivated for human consumption encompass a limited number of species, like lettuce, onion, tomato, maize, artichoke, strawberry, pepper and sweet potato (Table 1). Most of the data available on edible plant products have been obtained by studying single plant varieties, while only few works investigated the differential responses of cultivars/varieties belonging to the same species of food plants. For example, different mycorrhizal strawberry varieties did not show comparable levels of anthocyanins, anthocyanidins and vitamin $\mathrm{C}$ in fruits, while only some green and red leaf lettuce varieties contained larger amounts of anthocyanins, carotenoids, chlorophylls, tocopherol, and total phenolics, and showed a higher antioxidant activity, compared with control plants (Table 1). This represents a limitation of the studies performed so far, given the large number of old 
TABLE 1 | Secondary metabolites and antioxidant activities in mycorrhizal food plants.

\begin{tabular}{|c|c|c|c|c|c|}
\hline $\begin{array}{l}\text { Plant } \\
\text { species }\end{array}$ & $\begin{array}{l}\text { Variety or } \\
\text { cultivar }\end{array}$ & AMF species & $\begin{array}{l}\text { Measured } \\
\text { metabolites/antioxidant } \\
\text { activity assay } \\
\text { method }\end{array}$ & $\begin{array}{l}\text { Effect of AMF } \\
\text { inoculation }\end{array}$ & References \\
\hline \multicolumn{6}{|c|}{ (A) GREENHOUSE OR MESOCOSM EXPERIMENTS } \\
\hline \multicolumn{6}{|c|}{ Solanum lycopersicum L. } \\
\hline & $\begin{array}{l}\text { F1 Hybrid, } \\
\text { GS-15 }\end{array}$ & $\begin{array}{l}\text { Mix of: Glomus intraradices, } \\
\text { Glomus mosseae, Glomus } \\
\text { etunicatum (Soil and Water } \\
\text { Institute of Iran) }\end{array}$ & $\begin{array}{l}\text { Lycopene (FW) } \\
\text { DPPH }^{\mathrm{a}}\end{array}$ & $\begin{array}{l}\text { Increased concentration } \\
\text { Increased activity }\end{array}$ & $\begin{array}{l}\text { Ordookhani et al., } \\
2010\end{array}$ \\
\hline & Guadalete & $\begin{array}{l}\text { Mix of: Glomus mosseae, } \\
\text { Glomus caledonium, } \\
\text { Glomus viscosum, Glomus } \\
\text { intraradices, Glomus } \\
\text { coronatum }\end{array}$ & $\begin{array}{l}\text { Lycopene and } \\
\beta \text {-carotene } \\
\text { Lutein } \\
\text { Ascorbic acid }\end{array}$ & $\begin{array}{l}\text { No effect } \\
\text { No effect } \\
\text { Decreased concentration }\end{array}$ & $\begin{array}{l}\text { Copetta et al., } \\
2011\end{array}$ \\
\hline & Moneymaker & Glomus intraradices IMA6 & $\begin{array}{l}\text { Lycopene (FW) } \\
\text { Total phenols (FW) } \\
\text { Ascorbic acid (FW) } \\
\text { Glutathione (FW) } \\
\text { ABTS }^{b} \text { (FW) }\end{array}$ & $\begin{array}{l}\text { Increased concentration } \\
\text { No effect } \\
\text { No effect } \\
\text { No effect } \\
\text { No effect }\end{array}$ & $\begin{array}{l}\text { Giovannetti et al., } \\
2012\end{array}$ \\
\hline & Nemo-Netta & $\begin{array}{l}\text { Glomus mosseae (Biocult } \\
\text { Ltd., South Africa) }\end{array}$ & $\begin{array}{l}\text { Lycopene (FW) } \\
\text { Total flavonoids (FW) } \\
\text { Ascorbic acid (FW) } \\
\text { ABTS }\end{array}$ & $\begin{array}{l}\text { Increased concentration, } \\
\text { only at late inoculation time } \\
\text { No effect } \\
\text { No effect } \\
\text { No effect }\end{array}$ & $\begin{array}{l}\text { Nzanza et al., } \\
\text { 2012b }\end{array}$ \\
\hline & Moneymaker & $\begin{array}{l}\text { Funneliformis mosseae } \\
\text { BEG12 and/or Rhizophagus } \\
\text { irregularis BB-E } \\
\text { (Agrauxine, F) }\end{array}$ & Lycopene (FW) & $\begin{array}{l}\text { Mixed inoculation: no } \\
\text { effect; single isolate } \\
\text { inoculation: increased } \\
\text { concentration }\end{array}$ & Hart et al., 2015 \\
\hline & & & $\begin{array}{l}\beta \text {-carotene and } \\
\text { total carotenoids (FW) }\end{array}$ & $\begin{array}{l}\text { Mixed inoculation: } \\
\text { increased concentration; } \\
\text { single isolate inoculation: } \\
\text { no effect }\end{array}$ & \\
\hline & & & $\begin{array}{l}29 \text { Odor-active volatile } \\
\text { compounds }\end{array}$ & $\begin{array}{l}\text { Distinct phytochemical } \\
\text { profiles, but variable } \\
\text { quantitative effects }\end{array}$ & \\
\hline & Komeett & $\begin{array}{l}\text { Rhizophagus irregularis } \\
\text { (Premier Tech Inc., Canada) }\end{array}$ & $\begin{array}{l}\text { DPPH (DW) } \\
\text { Vitamins B1, B3, B5, } \\
\text { B6, ascorbic acid (FW) } \\
\text { Vitamin B6, ascorbic } \\
\text { acid (DW) } \\
\text { Total carotenoids (DW) }\end{array}$ & $\begin{array}{l}\text { No effect } \\
\text { No effect } \\
\text { Decreased concentration } \\
\text { Increased concentration }\end{array}$ & Hart et al., 2015 \\
\hline
\end{tabular}

Capsicum annuum L.

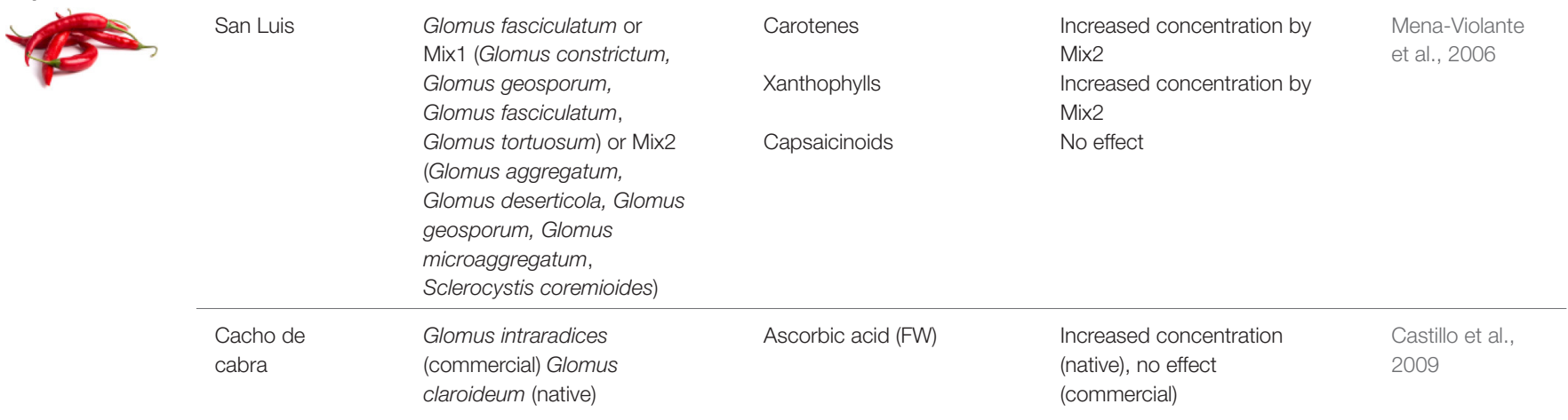


TABLE 1 | Continued

\begin{tabular}{|c|c|c|c|c|c|}
\hline $\begin{array}{l}\text { Plant } \\
\text { species }\end{array}$ & $\begin{array}{l}\text { Variety or } \\
\text { cultivar }\end{array}$ & AMF species & $\begin{array}{l}\text { Measured } \\
\text { metabolites/antioxidant } \\
\text { activity assay } \\
\text { method }\end{array}$ & $\begin{array}{l}\text { Effect of AMF } \\
\text { inoculation }\end{array}$ & References \\
\hline
\end{tabular}

Fragaria $\mathrm{x}$ ananassa Duch.

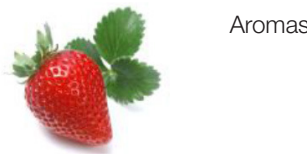

Glomus intraradices

(Premier Tech

Biotechnologies Company,

Canada)

method

\begin{tabular}{|c|c|c|c|c|}
\hline & & $\begin{array}{l}\text { Gallic, ferulic, ellagic } \\
\text { acids (DW) } \\
\text { Cyanidin-3-glucoside } \\
\text { (DW) } \\
\text { Pelargonidin-3- } \\
\text { glucoside (DW) } \\
\text { Quercetin and } \\
\text { kaempferol (DW) } \\
\text { Catechin (DW) }\end{array}$ & $\begin{array}{l}\text { No effect or decreased } \\
\text { concentration depending } \\
\text { on } \mathrm{N} \text { concentration } \\
\text { Increased concentration at } \\
\text { intermediate } \mathrm{N} \\
\text { No effect } \\
\text { Increased concentration at } \\
\text { intermediate } \mathrm{N} \\
\text { No effect }\end{array}$ & \\
\hline Selva & Mix (Mybasol, Italy) & $\begin{array}{l}\text { Pelargonidin } \\
\text { 3-glucoside, } \\
\text { Pelargonidin } \\
\text { 3-rutinoside and } \\
\text { pelargonidin malonyl } \\
\text { glucoside (FW) } \\
\text { Pelargonidin acetyl } \\
\text { glucoside and cyanidin } \\
\text { 3-glucoside (FW) } \\
\text { Total pelargonidins (FW) }\end{array}$ & $\begin{array}{l}\text { Increased concentration } \\
\text { No effect } \\
\text { Increased concentration }\end{array}$ & Lingua et al., 2013 \\
\hline Selva & $\begin{array}{l}\text { Mix of: Rhizophagus } \\
\text { intraradices, Glomus } \\
\text { aggregatum, Glomus } \\
\text { viscosum, Claroideoglomus } \\
\text { etunicatum, } \\
\text { Claroideoglomus } \\
\text { claroideum (Mybasol) }\end{array}$ & $\begin{array}{l}\text { Ascorbic acid (FW) } \\
\text { Folate (FW) }\end{array}$ & $\begin{array}{l}\text { Increased concentration } \\
\text { No effect }\end{array}$ & Bona et al., 2015 \\
\hline Fortuna & $\begin{array}{l}\text { Glomus iranicum var. } \\
\text { tenuihypharum } \\
\text { (Mycogrowth } ® \text {, Spain) }\end{array}$ & $\begin{array}{l}\text { Total phenols and } \\
\text { Anthocyanins (FW) }\end{array}$ & $\begin{array}{l}\text { Increased concentration at } \\
\text { early inoculation }\end{array}$ & $\begin{array}{l}\text { Cecatto et al., } \\
2016\end{array}$ \\
\hline Sabrina & & $\begin{array}{l}\text { Ascorbic acid (FW) } \\
\text { Total phenols, } \\
\text { anthocyanins and } \\
\text { ascorbic acid (FW) }\end{array}$ & $\begin{array}{l}\text { No effect } \\
\text { No effect }\end{array}$ & \\
\hline Splendor & & $\begin{array}{l}\text { Total phenols and } \\
\text { Ascorbic acid (FW) } \\
\text { Anthocyanins (FW) }\end{array}$ & $\begin{array}{l}\text { No effect } \\
\text { Decreased concentration }\end{array}$ & \\
\hline
\end{tabular}

\section{Lactuca sativa L.}

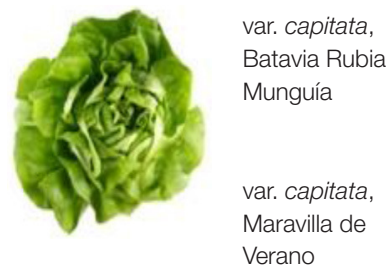

Glomus fasciculatum

Carotenoids (FW)

Increased concentration

Baslam et al.

Total phenols and depending on leaf position 2011 ascorbic acid (FW) Anthocyanins (FW)

Carotenoids, total No effect

No effect

Increased concentration at

Castellanos -coumaric acid (DW) intermedi orales et al. 2010 acid (FW)

Anthocyanins (FW)
Increased concentration

No effect

Increased concentration 
TABLE 1 | Continued

\begin{tabular}{|c|c|c|c|c|c|}
\hline $\begin{array}{l}\text { Plant } \\
\text { species }\end{array}$ & $\begin{array}{l}\text { Variety or } \\
\text { cultivar }\end{array}$ & AMF species & $\begin{array}{l}\text { Measured } \\
\text { metabolites/antioxidant } \\
\text { activity assay } \\
\text { method }\end{array}$ & $\begin{array}{l}\text { Effect of AMF } \\
\text { inoculation }\end{array}$ & References \\
\hline & $\begin{array}{l}\text { var. longifolia, } \\
\text { Cogollos de } \\
\text { Tudela }\end{array}$ & $\begin{array}{l}\text { Glomus fasciculatum or Mix } \\
\text { of: Glomus intraradices, } \\
\text { Glomus mosseae (Atens, } \\
\text { Spain) }\end{array}$ & $\begin{array}{l}\text { Carotenoids (FW) } \\
\text { Total phenols (FW) } \\
\text { Anthocyanins (FW) } \\
\text { Ascorbic acid (FW) }\end{array}$ & $\begin{array}{l}\text { No effect } \\
\text { Increased concentration in } \\
\text { outer leaves } \\
\text { Increased concentration in } \\
\text { inner leaves } \\
\text { Increased concentration in } \\
\text { inner leaves by } G \text {. } \\
\text { fasciculatum }\end{array}$ & \\
\hline & $\begin{array}{l}\text { Batavia Rubia } \\
\text { Munguía }\end{array}$ & $\begin{array}{l}\text { Mix of: Rhizophagus } \\
\text { intraradices, Funneliformis } \\
\text { mosseae (Atens) }\end{array}$ & $\begin{array}{l}\text { Carotenoids (FW) } \\
\text { Total phenols (FW) } \\
\text { Anthocyanins (FW) } \\
\text { Ascorbic acid (FW) }\end{array}$ & $\begin{array}{l}\text { Decreased concentration in } \\
\text { autumn in inner leaves and } \\
\text { increased in spring } \\
\text { No effect } \\
\text { Increased concentration in } \\
\text { winter and spring in inner } \\
\text { leaves } \\
\text { Increased concentration in } \\
\text { winter and spring in outer } \\
\text { leaves }\end{array}$ & $\begin{array}{l}\text { Baslam et al., } \\
2013\end{array}$ \\
\hline & $\begin{array}{l}\text { Maravilla de } \\
\text { Verano }\end{array}$ & & $\begin{array}{l}\text { Carotenoids (FW) } \\
\text { Total phenols (FW) } \\
\text { Anthocyanins (FW) } \\
\text { Ascorbic acid (FW) }\end{array}$ & $\begin{array}{l}\text { Increased concentration in } \\
\text { winter and spring in inner } \\
\text { leaves } \\
\text { No effect } \\
\text { Increased concentration in } \\
\text { winter in outer leaves and } \\
\text { spring in inner leaves } \\
\text { No effect }\end{array}$ & \\
\hline & $\begin{array}{l}\text { Batavia Rubia } \\
\text { Munguía and } \\
\text { Maravilla de } \\
\text { Verano }\end{array}$ & $\begin{array}{l}\text { Mix of: Rhizophagus } \\
\text { intraradices, Funneliformis } \\
\text { mosseae (Atens) }\end{array}$ & $\begin{array}{l}\text { Total carotenoids (DW) } \\
\text { Epidermal flavonols } \\
\text { Anthocyanins (by } \\
\text { optical monitoring) } \\
\text { Soluble phenols (DW) } \\
\text { DPPH (DW) }\end{array}$ & $\begin{array}{l}\text { Increased concentration in } \\
\text { Batavia Rubia Munguía } \\
\text { Decreased levels in Batavia } \\
\text { Rubia Munguía } \\
\text { No effect } \\
\text { No effect } \\
\text { Increased activity in Batavia } \\
\text { Rubia Munguía, decreased } \\
\text { in Maravilla de Verano }\end{array}$ & $\begin{array}{l}\text { Goicoechea et al., } \\
2015\end{array}$ \\
\hline & not available & Rhizophagus intraradices & $\begin{array}{l}\text { Superoxide dismutase } \\
\text { and catalase } \\
\text { Ascorbate peroxidase } \\
\text { Glutathione reductase } \\
\text { Total carotenoids (FW) }\end{array}$ & $\begin{array}{l}\text { Increased activity } \\
\text { Reduced activity } \\
\text { No effect } \\
\text { Increased concentration }\end{array}$ & Durán et al., 2016 \\
\hline & $\begin{array}{l}\text { var. crispa } \\
\text { Eluarde and } \\
\text { Panisse }\end{array}$ & $\begin{array}{l}\text { Funneliformis mosseae } \\
\text { AZ225C or Rhizoglomus } \\
\text { irregulare IMA6 (formerly } \\
\text { Glomus intraradices) }\end{array}$ & $\begin{array}{l}\text { ORACC }^{C}(\mathrm{FW}) \\
\text { Total phenolics (FW) } \\
\text { Total anthocyanins (FW) } \\
\text { (only Eluarde) }\end{array}$ & $\begin{array}{l}\text { Increased activity } \\
\text { Increased concentrations } \\
\text { with IMA6 } \\
\text { Increased concentrations }\end{array}$ & Avio et al., 2017 \\
\hline
\end{tabular}

\section{Ocimum basilicum L.}

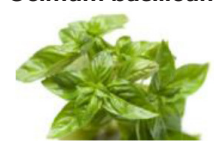

Genovese Glomus mosseae BEG 12 or Gigaspora margarita BEG

34, or Gigaspora rosea

Essential oils (13

Variable depending on

Copetta et al.,

phenolic compounds)

AMF and compound

2006, 2007

BEG 9

Genovese Glomus intraradices (Native

Italian and

Plants Incorporated, USA)

Total anthocyanins (FW)

Increased concentration in

Lee and Scagel

Purple Petra

Total phenolics and

Purple Petra

2009

phenolic acids (FW) 
TABLE 1 | Continued

\begin{tabular}{|c|c|c|c|c|c|}
\hline $\begin{array}{l}\text { Plant } \\
\text { species }\end{array}$ & $\begin{array}{l}\text { Variety or } \\
\text { cultivar }\end{array}$ & AMF species & $\begin{array}{l}\text { Measured } \\
\text { metabolites/antioxidant } \\
\text { activity assay } \\
\text { method }\end{array}$ & $\begin{array}{l}\text { Effect of AMF } \\
\text { inoculation }\end{array}$ & References \\
\hline & not available & $\begin{array}{l}\text { Glomus fasciculatum or } \\
\text { Glomus etunicatum or } \\
\text { Glomus intraradices }\end{array}$ & Total essential oils (DW) & $\begin{array}{l}\text { Increased concentration } \\
\text { and distinct phytochemical } \\
\text { profiles }\end{array}$ & $\begin{array}{l}\text { Rasouli- } \\
\text { Sadaghiani et al., } \\
2010\end{array}$ \\
\hline & $\begin{array}{l}\text { Cinnamon, } \\
\text { Siam Queen, } \\
\text { Sweet Dani } \\
\text { and Red } \\
\text { Rubin }\end{array}$ & $\begin{array}{l}\text { Rhizophagus intraradices } \\
\text { (Native Plants Incorporated) }\end{array}$ & $\begin{array}{l}\text { Total anthocyanins (FW) } \\
\text { Total phenolics (FW) } \\
\text { Phenolic acids (FW) } \\
\text { Total flavonoids (FW) }\end{array}$ & $\begin{array}{l}\text { Increased concentration in } \\
\text { Red Rubin } \\
\text { No effect } \\
\text { Increased concentration } \\
\text { No effect }\end{array}$ & $\begin{array}{l}\text { Scagel and Lee, } \\
2012\end{array}$ \\
\hline & $\begin{array}{l}\text { Tigullio and } \\
\text { Dark Opal }\end{array}$ & $\begin{array}{l}\text { Rhizoglomus irregulare } \\
\text { IMA6 (formerly Glomus } \\
\text { intraradices) }\end{array}$ & $\begin{array}{l}\text { ABTS (DW) } \\
\text { Total carotenoids (DW) } \\
\text { Total phenolics (DW) } \\
\text { Anthocyanins (DW) } \\
\text { (Dark Opal) } \\
\text { Rosmarinic acid (DW) }\end{array}$ & $\begin{array}{l}\text { No effect } \\
\text { Decreased concentration } \\
\text { No effect } \\
\text { Decreased concentration } \\
\text { Decreased concentration }\end{array}$ & $\begin{array}{l}\text { Battini et al., } \\
2016 b\end{array}$ \\
\hline
\end{tabular}

\section{Cynara cardunculus L. var. scolymus}

$\begin{array}{lll}\text { Terom } & \begin{array}{l}\text { Glomus mosseae AZ 225C } \\ \text { and/or Glomus intraradices } \\ \text { IMA6 }\end{array} & \begin{array}{l}\text { Total phenolics (FW) } \\ \text { and }\end{array} \\ & \text { DPPH }\end{array}$

and/or Glomus intraradices

DPPH
Increased concentration and activity with dual

inoculation and

G.intraradices
Ceccarelli et al., 2010

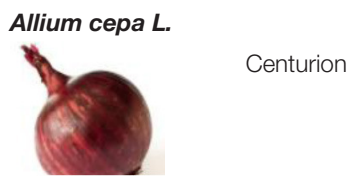

Mix of: Glomus mosseae, Glomus intraradices, Glomus claroideum, Glomus microaggregatum (Plantworks, UK)

\section{Organosulfur No effect compounds (as total pyruvic acid) and total phenolics (DW)

\section{Quercetin monoglycoside (DW) Quercetin diglycoside (DW) \\ ABTS and $\mathrm{ESR}^{\mathrm{d}}$ (DW)}

\begin{tabular}{|c|c|c|c|c|}
\hline & & $\begin{array}{l}\text { Quercetin } \\
\text { monoglycoside (DW) } \\
\text { Quercetin diglycoside } \\
\text { (DW) } \\
\text { ABTS and ESR }{ }^{d} \text { (DW) }\end{array}$ & $\begin{array}{l}\text { Increased concentration } \\
\text { when } \mathrm{NO}_{3}^{-}-\mathrm{N} \text { predominant } \\
\mathrm{No} \text { effect } \\
\text { Increased activity when } \\
\mathrm{NO}_{3}^{-}-\mathrm{N} \text { predominant }\end{array}$ & \\
\hline $\begin{array}{l}\text { Nasik red } \\
N-53\end{array}$ & $\begin{array}{l}\text { Mix of: Glomus intraradices, } \\
\text { Glomus mosseae }\end{array}$ & Total phenolics (FW) & Increased concentration & Lone et al., 2015 \\
\hline Alice & $\begin{array}{l}\text { Mix of: Glomus etunicatum, } \\
\text { Glomus microaggregatum, } \\
\text { Glomus intraradices, } \\
\text { Glomus claroideum, } \\
\text { Glomus mosseae, Glomus } \\
\text { geosporum (Symbivit, } \\
\text { Czech Rep.) or Glomus } \\
\text { intraradices BEG140 }\end{array}$ & $\begin{array}{l}\text { FRAP }^{\mathrm{e}} \\
\text { Ascorbic acid (FW) }\end{array}$ & $\begin{array}{l}\text { Increased activity with Mix } \\
\text { No effect }\end{array}$ & $\begin{array}{l}\text { Albrechtova et al., } \\
2012\end{array}$ \\
\hline $\begin{array}{l}\text { Stuttgarter } \\
\text { Riesen }\end{array}$ & $\begin{array}{l}\text { Mix of: Funneliformis } \\
\text { mosseae and Rhizophagus } \\
\text { irregularis (INOQ, Germany) }\end{array}$ & $\begin{array}{l}\text { Quercetin-diglucoside } \\
\text { and quercetin- } \\
\text { monoglucoside } \\
\text { Isorhamnetin-glucoside }\end{array}$ & $\begin{array}{l}\text { Increased concentration at } \\
\text { high inoculation amount } \\
\text { and when } \mathrm{NH}_{4}^{+}-\mathrm{N} \\
\text { predominant } \\
\text { No effect }\end{array}$ & $\begin{array}{l}\text { Mollavali et al., } \\
2018\end{array}$ \\
\hline
\end{tabular}

\section{Ipomea batatas L.}

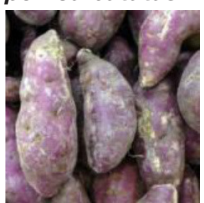

not available

Glomus intraradices (IFP

$\beta$-carotene (DW)

Increased concentration

Tong et al., 2013

Glomus mosseae (IFP GIm,

INOQ) 
TABLE 1 | Continued

\begin{tabular}{|c|c|c|c|c|c|}
\hline $\begin{array}{l}\text { Plant } \\
\text { species }\end{array}$ & $\begin{array}{l}\text { Variety or } \\
\text { cultivar }\end{array}$ & AMF species & $\begin{array}{l}\text { Measured } \\
\text { metabolites/antioxidant } \\
\text { activity assay } \\
\text { method }\end{array}$ & $\begin{array}{l}\text { Effect of AMF } \\
\text { inoculation }\end{array}$ & References \\
\hline \multicolumn{6}{|c|}{ (B) FIELD EXPERIMENTS } \\
\hline \multicolumn{6}{|c|}{ Solanum lycopersicum L. } \\
\hline & $\mathrm{PKM}-1$ & $\begin{array}{l}\text { Glomus intraradices \# } \\
\text { TNAU 120-02 }\end{array}$ & Ascorbic acid (FW) & Increased concentration & $\begin{array}{l}\text { Subramanian } \\
\text { et al., } 2006\end{array}$ \\
\hline & Vitella F1 & $\begin{array}{l}\text { Glomus sp. (Amykor, } \\
\text { Germany) }\end{array}$ & $\begin{array}{l}\text { Lycopene (FW) } \\
\beta \text {-carotene and } \\
\text { Total phenols (FW) }\end{array}$ & $\begin{array}{l}\text { Increased concentration } \\
\text { Increased concentration, } \\
\text { under organic } \\
\text { management }\end{array}$ & Ulrichs et al., 2008 \\
\hline & Nemo-Netta & $\begin{array}{l}\text { Glomus mosseae (Biocult } \\
\text { Ltd., South Africa) }\end{array}$ & Ascorbic acid (FW) & Increased concentration & $\begin{array}{l}\text { Nzanza et al., } \\
2012 a\end{array}$ \\
\hline & TC 2000 & $\begin{array}{l}\text { Mix of: Rhizophagus } \\
\text { intraradices, Glomus } \\
\text { aggregatum, Glomus } \\
\text { viscosum, Claroideoglomus } \\
\text { etunicatum and } \\
\text { Claroideoglomus } \\
\text { claroideum (Mybasol, Italy) }\end{array}$ & $\begin{array}{l}\text { Lycopene } \\
\beta \text {-carotene (FW) } \\
\text { Ascorbic acid (FW) }\end{array}$ & $\begin{array}{l}\text { No effect } \\
\text { No effect } \\
\text { Decreased concentration }\end{array}$ & Bona et al., 2017 \\
\hline & $\begin{array}{l}\text { Perfect Peel, } \\
\text { Roma, Rio } \\
\text { Grande }\end{array}$ & $\begin{array}{l}\text { Mix of: Rhizoglomus } \\
\text { irregulare IMA6 (formerly } \\
\text { Glomus intraradices), } \\
\text { Funneliformis mosseae } \\
\text { IMA1 }\end{array}$ & Lycopene (FW) & No effect & Njeru et al., 2017 \\
\hline
\end{tabular}

\section{Cynara cardunculus L. var. scolymus}

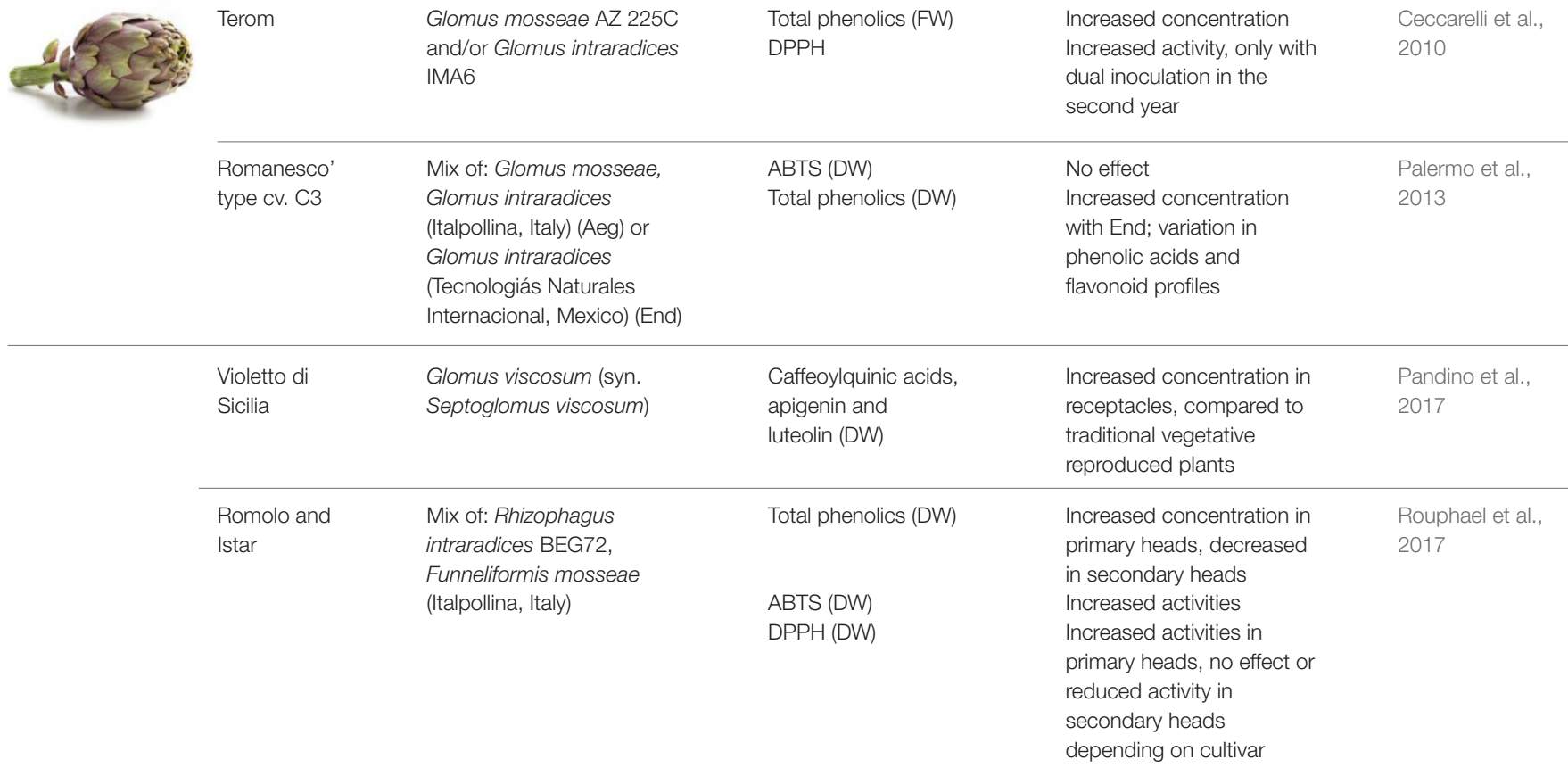

$\begin{array}{lll}\text { Allium cepa L. } & \text { Vaminoc (MicroBio, UK) or } & \text { Quercetin (FW) No effect } \\ \text { Glomus intraradices BEG87 } & \end{array}$


TABLE 1 | Continued

\begin{tabular}{|c|c|c|c|c|c|}
\hline $\begin{array}{l}\text { Plant } \\
\text { species }\end{array}$ & $\begin{array}{l}\text { Variety or } \\
\text { cultivar }\end{array}$ & AMF species & $\begin{array}{l}\text { Measured } \\
\text { metabolites/antioxidant } \\
\text { activity assay } \\
\text { method }\end{array}$ & $\begin{array}{l}\text { Effect of AMF } \\
\text { inoculation }\end{array}$ & References \\
\hline \multicolumn{6}{|c|}{ Ipomea batatas L. } \\
\hline & Hongxin & $\begin{array}{l}\text { Glomus etunicatum BEG } \\
\text { 168, Glomus etunicatum } \\
\text { HB-Bd45-Gsp4, Glomus } \\
\text { intraradices BEG 141, and a } \\
\text { mix of them (M3); Glomus } \\
\text { mosseae BEG 167, a mix of } \\
\text { M3 and BEG } 167 \text { (M4); mix } \\
\text { of : Glomus intraradices and } \\
\text { Glomus mosseae (Biorize, } \\
\text { France) }\end{array}$ & Carotene & No effect & Farmer et al., 2007 \\
\hline
\end{tabular}

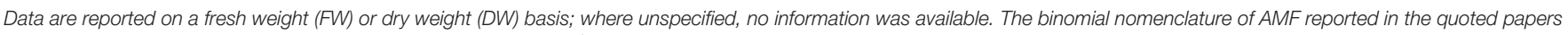

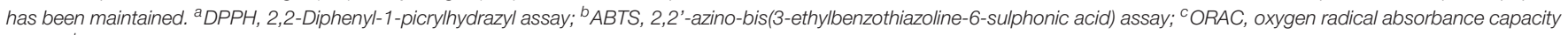
assay; ${ }^{d} E S R$, electron spin resonance spectroscopy; ${ }^{e}$ FRAP, ferric reducing ability of plasma assay.

and new varieties currently grown worldwide, which could be investigated and selected on the basis of their ability to produce beneficial compounds upon mycorrhizal inoculation. Such a selection would be particularly important for some vegetable species considered functional foods, i.e., globe artichoke, for its hepatoprotective, anticarcinogenic, antioxidative and antibacterial activities, and tomato, for its ability to reduce the risks of cancer and cardiovascular diseases (Canene-Adams et al., 2005). Indeed, artichoke and tomato showed higher antioxidant activity and enhanced levels of health-promoting compounds when produced by AMF-inoculated plants (Table 1).

The mechanistic explanation of the differential biosynthesis of secondary metabolites in mycorrhizal plants involves the activity of diverse enzymes leading to the production of terpenoids, flavonoids and the aminoacids tyrosine and phenylalanine, precursors of polyphenols in the phenylpropanoid pathway (Peipp et al., 1997; Walter et al., 2000; Lambais et al., 2003; Ponce et al., 2004; Herre et al., 2007; Pozo and AzconAguilar, 2007; López-Ráez et al., 2010a). Such molecules, often accumulated in plant resistance reaction to biotic and abiotic stresses, may be modulated by plant hormones such as ABA or jasmonates possibly involved in long distance signaling and in mycorrhizal priming of defense responses (Cameron et al., 2013; Adolfsson et al., 2017). Several gene expression studies showed a differential modulation of genes encoding for key enzymes of biochemical pathways leading to the production of healthpromoting secondary metabolites in food plants (Table 2) and model plant species (Harrison and Dixon, 1993, 1994; Bonanomi et al., 2001; Liu et al., 2007; Handa et al., 2015). In food plants, the use of the RNA-Seq technology, allowing investigations of whole transcripts, revealed that many genes, belonging to different functional classes, i.e., post-translational regulation, signaling, transport, biotic and abiotic stresses and hormone metabolism, were upregulated upon AMF inoculation and differentially expressed in fruits, leaves and roots, compared with controls (Table 2). Unfortunately, most of currently available RNA-Seq data assessing mycorrhizal regulated genes derive only from roots of the investigated plants, such as Citrus sinensis, Cucumis sativus, Helianthus annuus, Litchi chinensis, Oryza sativa, and Vitis vinifera (Table 2). Since the different genes may be differentially expressed in the diverse plant organs, further works should focus on the edible parts of food plants, in order to obtain information on the genes regulating the production of health-promoting compounds, modulated by mycorrhizal symbioses. In addition, the functional significance of fungal symbiont identity in the modulation of phytochemicals production should be deeply investigated, as large variations in gene expression were detected in model plants inoculated with different AMF (Burleigh et al., 2002; Hohnjec et al., 2005; Deguchi et al., 2007; Massoumou et al., 2007).

\section{FUNCTIONAL DIVERSITY OF AMF}

A number of studies have been carried out in order to select the optimal host/fungus combinations leading to the best plant performance, in terms of growth and nutrition. Different strategies have been proposed to detect the criteria for the selection of infective and efficient strains to be used for inoculation in diverse host plants and soil conditions. The possibility of implementing AMF inoculation depends first and foremost on the availability of strains able to establish rapidly an extensive colonization in the roots of a host plant and to compete for infection sites with indigenous AMF endophytes. Despite the obligately biotrophic status of AMF, involving labor-intensive experiments, progress has been done in the determination of the parameters that, in many different AMF isolate, affect spore dormancy and germination, pre-symbiotic mycelial growth, appressorium formation and intraradical development (Giovannetti et al., 2010). As to the selection of efficient isolates, the great majority of studies assessed their efficiency in terms of host growth responses, nutrient uptake, in particular $\mathrm{P}$ and $\mathrm{N}$, and consequently considered the relevant fungal parameters, such as the extent and viability of 
TABLE 2 | Genes involved in the biosynthesis of health-promoting secondary metabolites, which are upregulated in above- or belowground cell tissues of mycorrhizal food plants.

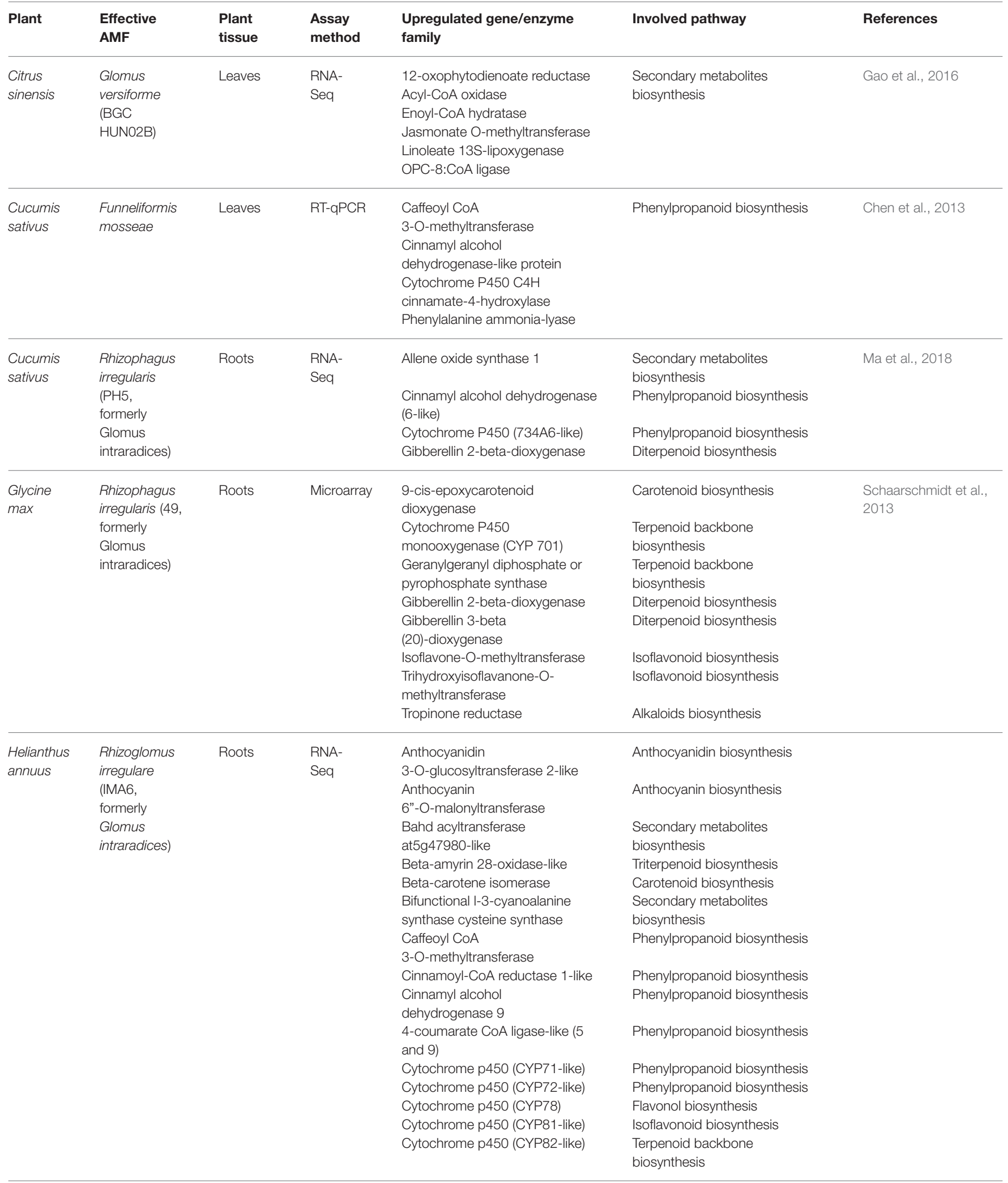


TABLE 2 | Continued

\begin{tabular}{|c|c|c|c|c|c|c|}
\hline Plant & $\begin{array}{l}\text { Effective } \\
\text { AMF }\end{array}$ & $\begin{array}{l}\text { Plant } \\
\text { tissue }\end{array}$ & $\begin{array}{l}\text { Assay } \\
\text { method }\end{array}$ & $\begin{array}{l}\text { Upregulated gene/enzyme } \\
\text { family }\end{array}$ & Involved pathway & References \\
\hline & & & & $\begin{array}{l}\text { Cytochrome p450 (CYP93A-like) } \\
\text { Ent-kaurene oxidase cyp701a5 } \\
\text { Flavanone 3-hydroxylase } \\
\text { Flavonoid glucosyltransferase } \\
\text { Flavonoid peroxidase 1 } \\
\text { Geraniol 8-hydroxylase-like } \\
\text { Gibberellin 2-beta-dioxygenase } \\
\text { Gibberellin 3-beta } \\
\text { (20)-dioxygenase } \\
\text { Hydroxycinnamoyl transferase } \\
\text { Hyoscyamine 6-dioxygenase } \\
\text { Isoleucine N-monooxygenase } \\
\text { Pelargonidin } \\
\text { 3-o-(6-caffeoylglucoside) } \\
\text { 5-o-(6-o-malonylglucoside) } \\
\text { 4-malonyltransferase-like } \\
\text { Shikimate o- } \\
\text { hydroxycinnamoyltransferase-like } \\
\text { Tetrahydrocannabinolic acid } \\
\text { synthase-like } \\
\text { Tropinone reductase homolog } \\
\text { Valine N-monooxygenase } \\
\text { (CYP79D1-2) } \\
\text { Zeatin-O-xylosyltransferase-like }\end{array}$ & $\begin{array}{l}\text { Isoflavonoid biosynthesis } \\
\text { Diterpenoid biosynthesis } \\
\text { Flavonoid biosynthesis } \\
\text { Flavonoid biosynthesis } \\
\text { Flavonoid biosynthesis } \\
\text { Monoterpenoid biosynthesis } \\
\text { Diterpenoid biosynthesis } \\
\text { Diterpenoid biosynthesis } \\
\text { Phenylpropanoid biosynthesis } \\
\text { Alkaloid biosynthesis } \\
\text { Glucosinolate biosynthesis } \\
\text { Anthocyanin biosynthesis } \\
\text { Flavonoid biosynthesis } \\
\text { Cannabinoid biosynthesis } \\
\text { Alkaloids biosynthesis } \\
\text { Glucosinolate biosynthesis } \\
\text { Secondary metabolites } \\
\text { biosynthesis }\end{array}$ & Vangelisti et al., 2018 \\
\hline $\begin{array}{l}\text { Litchi } \\
\text { chinensis }\end{array}$ & $\begin{array}{l}\text { native AMF } \\
\text { community }\end{array}$ & Roots & $\begin{array}{l}\text { RNA- } \\
\text { Seq }\end{array}$ & $\begin{array}{l}\text { Anthocyanidin reductase } \\
\text { Bifunctional dihydroflavonol } \\
\text { 4-reductase/flavanone } \\
\text { 4-reductase } \\
\text { Caffeic acid } \\
\text { 3-O-methyltransferase } \\
\text { Carotenoid cleavage } \\
\text { dioxygenase } 7 \\
\text { Chalcone synthase } \\
\text { Coumarate-CoA ligase } 2 \\
\text { Cytochrome P450 (CYP73A) } \\
\text { Flavanone 3-dioxygenase } \\
\text { Flavonoid 3'-monooxygenase } \\
\\
\text { Leucoanthocyanidin reductase } \\
\text { Naringenin,2-oxoglutarate } \\
\text { 3-dioxygenase } \\
\text { Peroxidase } 53 \\
\text { Tropinone reductase }\end{array}$ & $\begin{array}{l}\text { Flavonoid biosynthesis } \\
\text { Flavonoid biosynthesis } \\
\text { Phenylpropanoid biosynthesis } \\
\text { Carotenoid biosynthesis } \\
\text { Flavonoid biosynthesis } \\
\text { Phenylpropanoid biosynthesis } \\
\text { Phenylpropanoid biosynthesis } \\
\text { Flavonoid biosynthesis } \\
\text { Flavonoid, flavone, flavonol } \\
\text { biosynthesis } \\
\text { Flavonoid biosynthesis } \\
\text { Flavonoid biosynthesis } \\
\text { Phenylpropanoid biosynthesis } \\
\text { Alkaloid biosynthesis }\end{array}$ & 西 \\
\hline $\begin{array}{l}\text { Ocimum } \\
\text { basilicum }\end{array}$ & $\begin{array}{l}\text { Rhizoglomus } \\
\text { irregulare } \\
\text { (IMA6, } \\
\text { formerly } \\
\text { Glomus } \\
\text { intraradices) }\end{array}$ & Leaves & RT-qPCR & Tyrosine amino-transferase & Tyrosine metabolism & Battini et al., 2016a \\
\hline $\begin{array}{l}\text { Oryza } \\
\text { sativa }\end{array}$ & $\begin{array}{l}\text { Glomus } \\
\text { intraradices } \\
\text { (DAOM197198) }\end{array}$ & Leaves & Macroarray & $\begin{array}{l}\text { Ascorbate peroxidase (APX8) } \\
\text { Cytochrome P450 } \\
\text { Dehydroascorbate reductase } \\
\text { Squalene monooxygenase }\end{array}$ & $\begin{array}{l}\text { Ascorbate and aldarate } \\
\text { metabolism } \\
\text { Phenylpropanoid biosynthesis } \\
\text { Ascorbate and aldarate } \\
\text { metabolism } \\
\text { Secondary metabolites } \\
\text { biosynthesis }\end{array}$ & $\begin{array}{l}\text { Campos-Soriano et al., } \\
2012\end{array}$ \\
\hline
\end{tabular}


TABLE 2 | Continued

\begin{tabular}{|c|c|c|c|c|c|c|}
\hline Plant & $\begin{array}{l}\text { Effective } \\
\text { AMF }\end{array}$ & $\begin{array}{l}\text { Plant } \\
\text { tissue }\end{array}$ & $\begin{array}{l}\text { Assay } \\
\text { method }\end{array}$ & $\begin{array}{l}\text { Upregulated gene/enzyme } \\
\text { family }\end{array}$ & Involved pathway & References \\
\hline & $\begin{array}{l}\text { Rhizophagus } \\
\text { irregularis } \\
\text { (DAOM197198) }\end{array}$ & Roots & $\begin{array}{l}\text { RNA- } \\
\text { Seq }\end{array}$ & $\begin{array}{l}\text { Anthocyanidin } \\
\text { 3-O-glucosyltransferase } \\
\text { Cinnamoyl-CoA reductase } \\
\text { cytochrome P450 } \\
\text { Ent-kaurene synthase } \\
\text { Flavonol synthase/flavanone } \\
\text { 3-hydroxylase } \\
\text { Laccase precursor protein } \\
\text { Mannose-6-phosphate } \\
\text { isomerase } \\
\text { Oxidoreductase, aldo/keto } \\
\text { reductase family protein } \\
\text { Phytoene synthase } \\
\text { Terpene synthase }\end{array}$ & $\begin{array}{l}\text { Anthocyanin biosynthesis } \\
\text { Phenylpropanoid biosynthesis } \\
\text { Phenylpropanoid biosynthesis } \\
\text { Diterpenoid biosynthesis } \\
\text { Flavonoid biosynthesis } \\
\text { Ascorbate and aldarate } \\
\text { metabolism } \\
\text { Ascorbate and aldarate } \\
\text { metabolism } \\
\text { Retinoic acid biosynthesis } \\
\text { Carotenoid biosynthesis } \\
\text { Diterpenoid biosynthesis }\end{array}$ & Fiorilli et al., 2015 \\
\hline & $\begin{array}{l}\text { Glomus } \\
\text { intraradices }\end{array}$ & Roots & Microarray & $\begin{array}{l}\text { Cinnamoyl-CoA reductase } \\
\text { 4-coumarate CoA ligase } \\
\text { Cycloartenol synthase } \\
\text { Cytochrome p450 } \\
\text { Flavonoid } 3^{\prime}, 5^{\prime} \text {-hydroxylase } \\
\text { Geranylgeranyl diphosphate } \\
\text { synthase }\end{array}$ & $\begin{array}{l}\text { Phenylpropanoid biosynthesis } \\
\text { Phenylpropanoid biosynthesis } \\
\text { Secondary metabolites } \\
\text { biosynthesis } \\
\text { Phenylpropanoid biosynthesis } \\
\text { Flavonoid biosynthesis } \\
\text { Terpenoid backbone } \\
\text { biosynthesis }\end{array}$ & Güimil et al., 2005 \\
\hline & $\begin{array}{l}\text { Rhizophagus } \\
\text { irregularis }\end{array}$ & Roots & Microarray & $\begin{array}{l}\text { 4-coumarate-CoA ligase } \\
\text { Caffeoyl CoA } \\
\text { 3-O-methyltransferase } \\
\text { Gibberellin 2-beta-dioxygenase } \\
\text { p-coumaroyl-CoA:caffeoyl-CoA } \\
\text { 3-hydroxylase }\end{array}$ & $\begin{array}{l}\text { Phenylpropanoid biosynthesis } \\
\text { Phenylpropanoid biosynthesis } \\
\text { Diterpenoid biosynthesis } \\
\text { Phenylpropanoid biosynthesis }\end{array}$ & Gutjahr et al., 2015 \\
\hline $\begin{array}{l}\text { Pisum } \\
\text { sativum }\end{array}$ & $\begin{array}{l}\text { Glomus } \\
\text { mosseae } \\
\text { (BB-E-Sc-02; } \\
\text { Biorize, Dijon, } \\
\text { FR) }\end{array}$ & Roots & SSH & $\begin{array}{l}\text { Beta-cyanoalanine synthase } \\
\text { Neoxanthin (clavage enzyme) } \\
\text { synthase }\end{array}$ & $\begin{array}{l}\text { Secondary metabolites } \\
\text { biosynthesis } \\
\text { Carotenoid biosynthesis }\end{array}$ & Grunwald et al., 2004 \\
\hline \multirow[t]{2}{*}{$\begin{array}{l}\text { Solanum } \\
\text { lycopersicum }\end{array}$} & $\begin{array}{l}\text { Rhizophagus } \\
\text { irregularis }\end{array}$ & Leaves & $\begin{array}{l}\text { RNA- } \\
\text { Seq }\end{array}$ & $\begin{array}{l}\text { 4-coumarate CoA ligase } \\
\text { Acyltransferase-like protein } \\
\text { Caffeoyl CoA } \\
\text { 3-O-methyltransferase } \\
\text { Cinnamoyl CoA-reductase-like } \\
\text { Cytochrome P450 } \\
\text { NADPH-reductase } \\
\text { Hydroxycinnamoyl transferase } \\
\text { Hydroxycinnamoyl-CoA } \\
\text { shikimate/quinate } \\
\text { hydroxycinnamoyltransferase } \\
\text { Mevalonate kinase } \\
\text { Phenylalanine ammonia-lyase } \\
\text { Undecaprenyl pyrophosphate } \\
\text { synthase }\end{array}$ & $\begin{array}{l}\text { Phenylpropanoid biosynthesis } \\
\text { Phenylpropanoid biosynthesis } \\
\text { Phenylpropanoid biosynthesis } \\
\text { Flavonoid biosynthesis } \\
\text { Phenylpropanoid biosynthesis } \\
\text { Phenylpropanoid biosynthesis } \\
\text { Phenylpropanoid biosynthesis } \\
\text { Terpenoid backbone } \\
\text { biosynthesis } \\
\text { Phenylpropanoid biosynthesis } \\
\text { Terpenoid backbone } \\
\text { biosynthesis }\end{array}$ & $\begin{array}{l}\text { Cervantes-Gámez } \\
\text { et al., } 2016\end{array}$ \\
\hline & $\begin{array}{l}\text { Glomus } \\
\text { intraradices } \\
\text { (BEG141) }\end{array}$ & Roots & Microarray & $\begin{array}{l}\text { Carotenoid cleavage } \\
\text { dioxygenase } \\
\text { Cytochrome P450 } \\
\text { Mevalonate disphosphate } \\
\text { decarboxylase } \\
\text { Phytoene dehydrogenase }\end{array}$ & $\begin{array}{l}\text { Carotenoid biosynthesis } \\
\text { Phenylpropanoid biosynthesis } \\
\text { Carotenoid biosynthesis } \\
\text { Carotenoid biosynthesis }\end{array}$ & Dermatsev et al., 2010 \\
\hline
\end{tabular}


TABLE 2 | Continued

\begin{tabular}{|c|c|c|c|c|c|c|}
\hline Plant & $\begin{array}{l}\text { Effective } \\
\text { AMF }\end{array}$ & $\begin{array}{l}\text { Plant } \\
\text { tissue }\end{array}$ & $\begin{array}{l}\text { Assay } \\
\text { method }\end{array}$ & $\begin{array}{l}\text { Upregulated gene/enzyme } \\
\text { family }\end{array}$ & Involved pathway & References \\
\hline & $\begin{array}{l}\text { Glomus } \\
\text { mosseae } \\
\text { (BEG12) }\end{array}$ & Roots & $\begin{array}{l}\text { RNA- } \\
\text { Seq }\end{array}$ & $\begin{array}{l}\text { (-)-a-terpineol synthase } \\
\text { (+)-delta-cadinene synthase } \\
\text { 4-coumarate CoA ligase } \\
\text { Anthocyanidin synthase } \\
\text { Carotenoid cleavage } \\
\text { dioxygenase } 1 \\
\text { Cytochrome P450 } \\
\text { Cytochrome p450 } \\
\text { monooxygenase cyp72a59 } \\
\text { Monoterpene } \\
\text { glucosyltransferase } \\
\text { Phenylalanine ammonia-lyase } \\
\text { Phytoene synthase } \\
\text { Sesquiterpene synthase }\end{array}$ & $\begin{array}{l}\text { Terpenoid backbone } \\
\text { biosynthesis } \\
\text { Terpenoid backbone } \\
\text { biosynthesis } \\
\text { Phenylpropanoid biosynthesis } \\
\text { Flavonoid biosynthesis } \\
\text { Carotenoid biosynthesis } \\
\text { Phenylpropanoid biosynthesis } \\
\text { Phenylpropanoid biosynthesis } \\
\text { Terpenoid backbone } \\
\text { biosynthesis } \\
\text { Phenylpropanoid biosynthesis } \\
\text { Carotenoid biosynthesis } \\
\text { Terpenoid backbone } \\
\text { biosynthesis }\end{array}$ & \multirow[t]{2}{*}{ Fiorilli et al., 2009} \\
\hline & $\begin{array}{l}\text { Glomus } \\
\text { mosseae } \\
\text { (BEG12) }\end{array}$ & Shoots & $\begin{array}{l}\text { RNA- } \\
\text { Seq }\end{array}$ & $\begin{array}{l}\text { Caffeic acid } \\
\text { 3-O-methyltransferase } \\
\text { Cytochrome p450 } \\
\text { Tropinone reductase }\end{array}$ & Phenylpropanoid biosynthesis & \\
\hline & $\begin{array}{l}\text { Glomus } \\
\text { irregulare } \\
\text { (DAOM } \\
197198)\end{array}$ & Roots & Microarray & $\begin{array}{l}\text { Allene oxide synthase } 3 \\
\text { Gibberellin 3-beta-dioxygenase } \\
\text { Phytoene desaturase }\end{array}$ & $\begin{array}{l}\text { Secondary metabolites } \\
\text { biosynthesis } \\
\text { Carotenoid biosynthesis } \\
\text { Carotenoid biosynthesis }\end{array}$ & Garrido et al., 2010 \\
\hline & $\begin{array}{l}\text { Glomus } \\
\text { intraradices }\end{array}$ & Roots & Microarray & $\begin{array}{l}\text { Deoxy-D-xylulose-5-phosphate } \\
\text { reductoisomerase } \\
\text { Gibberellin 2-beta-dioxygenase } \\
\text { Hydroxycinnamoyl/benzoyl } \\
\text { transferase } \\
\text { Lycopene b-cyclase } \\
\text { Phytoene desaturase } \\
\text { z-carotene desaturase }\end{array}$ & $\begin{array}{l}\text { Terpenoid backbone } \\
\text { biosynthesis } \\
\text { Diterpenoid biosynthesis } \\
\text { Phenylpropanoid biosynthesis } \\
\text { Carotenoid biosynthesis } \\
\text { Carotenoid biosynthesis } \\
\text { Carotenoid biosynthesis }\end{array}$ & \multirow[t]{3}{*}{$\begin{array}{l}\text { López-Ráez et al., } \\
2010 b\end{array}$} \\
\hline & $\begin{array}{l}\text { intraradices/Glomus } \\
\text { mosseae }\end{array}$ & Roots & Microarray & $\begin{array}{l}\text { Allene oxide synthase 1-3 } \\
\text { Antocyanin acyltrasferase } \\
\text { Cytochrome P450 } \\
\text { monooxygenase (CYP 81, } \\
\text { CYP721) } \\
\text { 1-deoxy-D-xylulose 5-phosphate } \\
\text { synthase } \\
\text { Gibberellin 3-beta } \\
\text { (20)-dioxygenase }\end{array}$ & $\begin{array}{l}\text { Secondary metabolites } \\
\text { biosynthesis } \\
\text { Anthocyanidin biosynthesis } \\
\text { Terpenoid backbone } \\
\text { biosynthesis } \\
\text { Terpenoid backbone } \\
\text { biosynthesis } \\
\text { Diterpenoid biosynthesis }\end{array}$ & \\
\hline & $\begin{array}{l}\text { Glomus } \\
\text { mosseae }\end{array}$ & Roots & Microarray & Polyphenol oxidase & $\begin{array}{l}\text { Secondary metabolites } \\
\text { biosynthesis }\end{array}$ & \\
\hline & $\begin{array}{l}\text { Glomus } \\
\text { mosseae }\end{array}$ & Fruit & Microarray & Histidine decarboxylase & $\begin{array}{l}\text { Secondary metabolites } \\
\text { biosynthesis }\end{array}$ & Salvioli et al., 2012 \\
\hline & $\begin{array}{l}\text { Rhizophagus } \\
\text { irregularis } \\
\text { (DAOM } \\
\text { 197198) }\end{array}$ & Roots & $\begin{array}{l}\text { RNA- } \\
\text { Seq }\end{array}$ & $\begin{array}{l}\text { Carotenoid cleavage } \\
\text { dioxygenase } 8 \\
\text { Cytochrome P450 (CYP93A1) }\end{array}$ & $\begin{array}{l}\text { Carotenoid biosynthesis } \\
\text { Flavonoid biosynthesis }\end{array}$ & $\begin{array}{l}\text { Sugimura and Saito, } \\
2017\end{array}$ \\
\hline & $\begin{array}{l}\text { Funneliformis } \\
\text { mosseae } \\
\text { (BEG12) }\end{array}$ & Fruit & $\begin{array}{l}\text { RNA- } \\
\text { Seq }\end{array}$ & Terpene synthase & Diterpenoid biosynthesis & Zouari et al., 2014 \\
\hline
\end{tabular}


TABLE 2 | Continued

\begin{tabular}{|c|c|c|c|c|c|c|}
\hline Plant & $\begin{array}{l}\text { Effective } \\
\text { AMF }\end{array}$ & $\begin{array}{l}\text { Plant } \\
\text { tissue }\end{array}$ & $\begin{array}{l}\text { Assay } \\
\text { method }\end{array}$ & $\begin{array}{l}\text { Upregulated gene/enzyme } \\
\text { family }\end{array}$ & Involved pathway & References \\
\hline \multirow[t]{26}{*}{$\begin{array}{l}\text { Solanum } \\
\text { tuberosum }\end{array}$} & $\begin{array}{l}\text { Glomus sp. } \\
\text { MUCL } 41833\end{array}$ & Roots & Microarray & $\begin{array}{l}\text { Anthocyanidin-3-glucoside } \\
\text { rhamnosyltransferase }\end{array}$ & Anthocyanin biosynthesis & Gallou et al., 2012 \\
\hline & & & & Anthranilate & Secondary metabolites & \\
\hline & & & & $\begin{array}{l}\mathrm{N} \text {-hydroxycinnamoyl/ } \\
\text { benzoyltransferase }\end{array}$ & biosynthesis & \\
\hline & & & & $\begin{array}{l}\text { Benzyl alcohol benzoyl } \\
\text { transferase }\end{array}$ & Phenylpropanoid biosynthesis & \\
\hline & & & & Carotenoid isomerase & Carotenoid biosynthesis & \\
\hline & & & & Catechol oxidase & Isoquinoline alkaloid biosynthesis & \\
\hline & & & & Chalcone reductase & Flavonoid biosynthesis & \\
\hline & & & & Coumarate-CoA ligase (2-4) & Phenylpropanoid biosynthesis & \\
\hline & & & & Cytochrome p450 (CYP71-like) & Phenylpropanoid biosynthesis & \\
\hline & & & & Flavanone 3-hydroxylase & Flavonoid biosynthesis & \\
\hline & & & & $\begin{array}{l}\text { Flavonoid 1-2 } \\
\text { rhamnosyltransferase }\end{array}$ & Flavonoid biosynthesis & \\
\hline & & & & Flavonoid 3'-monooxygenase & $\begin{array}{l}\text { Flavonoid, flavone, flavonol } \\
\text { biosynthesis }\end{array}$ & \\
\hline & & & & $\begin{array}{l}\text { Geranylgeranyl pyrophosphate } \\
\text { synthase } 1\end{array}$ & $\begin{array}{l}\text { Terpenoid backbone } \\
\text { biosynthesis }\end{array}$ & \\
\hline & & & & Gibberellin 2-beta-dioxygenase & Diterpenoid biosynthesis & \\
\hline & & & & Hydroxycinnamoyl transferase & Phenylpropanoid biosynthesis & \\
\hline & & & & $\begin{array}{l}\text { Leucoanthocyanidin } \\
\text { dioxygenase-like }\end{array}$ & Anthocyanidin biosynthesis & \\
\hline & & & & Orcinol O-methyltransferase & $\begin{array}{l}\text { Secondary metabolites } \\
\text { biosynthesis }\end{array}$ & \\
\hline & & & & Peroxidase (Class III) & Phenylpropanoid biosynthesis & \\
\hline & & & & Phenylalanine ammonia-lyase & Phenylpropanoid biosynthesis & \\
\hline & & & & Phytoene desaturase & Carotenoid biosynthesis & \\
\hline & & & & $\begin{array}{l}\text { Hyoscyamine } 6 \\
\text { beta-hydroxylase-like }\end{array}$ & Alkaloid biosynthesis & \\
\hline & & & & Sesquiterpene synthase 2 & $\begin{array}{l}\text { Terpenoid backbone } \\
\text { biosynthesis }\end{array}$ & \\
\hline & & & & Tropinone reductase I & Alkaloids biosynthesis & \\
\hline & & & & $\begin{array}{l}\text { Tyramine hydroxycinnamoyl } \\
\text { transferase }\end{array}$ & Phenylpropanoid biosynthesis & \\
\hline & & & & Vetispiradiene synthase & $\begin{array}{l}\text { Terpenoid backbone } \\
\text { biosynthesis }\end{array}$ & \\
\hline & & & & z-carotene desaturase & Carotenoid biosynthesis & \\
\hline
\end{tabular}

\begin{tabular}{|c|c|c|c|c|c|c|}
\hline \multirow[t]{3}{*}{$\begin{array}{l}\text { Vitis } \\
\text { vinifera }\end{array}$} & $\begin{array}{l}\text { Funneliformis } \\
\text { mosseae } \\
\text { (BEG12) }\end{array}$ & Roots & $\begin{array}{l}\text { RNA- } \\
\text { Seq }\end{array}$ & $\begin{array}{l}\text { ABA 8' -hydroxylase CYP707A1 } \\
\text { Alliin lyase precursor }\end{array}$ & $\begin{array}{l}\text { Carotenoid biosynthesis } \\
\text { Secondary metabolites } \\
\text { biosynthesis }\end{array}$ & Balestrini et al., 2017 \\
\hline & $\begin{array}{l}\text { Funneliformis } \\
\text { mosseae } \\
\text { (BEG12)/MICOSAT } \\
\text { F® Vite } \\
\text { (CCS-Aosta) }\end{array}$ & Roots & $\begin{array}{l}\text { RNA- } \\
\text { Seq }\end{array}$ & $\begin{array}{l}\text { 4-coumarate-CoA ligase } \\
\text { ABA 8'-hydroxylase CYP707A1 } \\
\text { Cinnamyl alcohol dehydrogenase } \\
\text { Taxane 10-beta-hydroxylase } \\
\text { Tropinone reductase } \\
\text { Urophorphyrin III methylase }\end{array}$ & $\begin{array}{l}\text { Terpenoid-quinone biosynthesis } \\
\text { Carotenoid biosynthesis } \\
\text { Phenylpropanoid biosynthesis } \\
\text { Carotenoid biosynthesis } \\
\text { Alkaloids biosynthesis } \\
\text { Secondary metabolites } \\
\text { biosynthesis }\end{array}$ & \\
\hline & $\begin{array}{l}\text { MICOSAT F® } \\
\text { Vite } \\
\text { (CCS-Aosta) }\end{array}$ & Roots & $\begin{array}{l}\text { RNA- } \\
\text { Seq }\end{array}$ & Methyl jasmonate esterase & $\begin{array}{l}\text { Secondary metabolites } \\
\text { biosynthesis }\end{array}$ & \\
\hline $\begin{array}{l}\text { Zea } \\
\text { mays }\end{array}$ & $\begin{array}{l}\text { Rhizophagus } \\
\text { irregularis }\end{array}$ & Leaves & Microarray & $\begin{array}{l}\text { 1-aminocyclopropane-1- } \\
\text { carboxylate oxidase } \\
\text { 3-hydroxy-3-methylglutaryl- } \\
\text { reductase } \\
\text { Alliin lyase }\end{array}$ & $\begin{array}{l}\text { Cysteine and methionine } \\
\text { metabolism } \\
\text { Terpenoid backbone } \\
\text { biosynthesis } \\
\text { Secondary metabolites } \\
\text { biosynthesis }\end{array}$ & Gerlach et al., 2015 \\
\hline
\end{tabular}


TABLE 2 | Continued

\begin{tabular}{|c|c|c|c|c|c|c|}
\hline Plant & $\begin{array}{l}\text { Effective } \\
\text { AMF }\end{array}$ & $\begin{array}{l}\text { Plant } \\
\text { tissue }\end{array}$ & $\begin{array}{l}\text { Assay } \\
\text { method }\end{array}$ & $\begin{array}{l}\text { Upregulated gene/enzyme } \\
\text { family }\end{array}$ & Involved pathway & References \\
\hline & & & & $\begin{array}{l}\text { Anthocyanidin } \\
\text { 3-O-glucosyltransferase } 2\end{array}$ & Anthocyanin biosynthesis & \\
\hline & & & & Beta-carotene hydroxylase 1 & Carotenoid biosynthesis & \\
\hline & & & & Cytochrome p450 71a1 & Phenylpropanoid biosynthesis & \\
\hline & & & & $\begin{array}{l}\text { Farnesyl pyrophosphate } \\
\text { synthetase }\end{array}$ & $\begin{array}{l}\text { Terpenoid backbone } \\
\text { biosynthesis }\end{array}$ & \\
\hline & & & & $\begin{array}{l}\text { Homogentisate phytyltransferase } \\
\text { vte2-1 }\end{array}$ & Terpenoid-quinone biosynthesis & \\
\hline & & & & Mevalonate kinase & $\begin{array}{l}\text { Terpenoid backbone } \\
\text { biosynthesis }\end{array}$ & \\
\hline & & & & $\begin{array}{l}\text { Short-chain dehydrogenase } \\
\text { reductase family protein }\end{array}$ & Retinoic acid biosynthesis & \\
\hline
\end{tabular}

The binomial nomenclature of arbuscular mycorrhizal fungi (AMF) reported in the quoted papers has been maintained. Assay methods: RNA sequencing (RNA-Seq), quantitative reverse transcription PCR (RT-qPCR), suppression subtractive hybridization (SSH).

ERM exploring the soil, the rate of absorption, translocation and transfer of mineral nutrients, from hyphae to plant root cells (Giovannetti and Avio, 2002; Ezawa and Saito, 2018).

Only few works studied the differential efficiency of the diverse AMF isolates in relation to the production of health-promoting phytochemicals. The first studies reported higher contents of essential oils in coriander shoots and fruits when inoculated with Rhizoglomus fasciculatum compared with Glomus macrocarpum, that modified also the essential oil profiles, with increased concentrations of linalool and geraniol, respectively (Kapoor et al., 2002b). By contrast, the same AMF species produced completely opposite results with dill and carum plants, where G. macrocarpum was more efficient in enhancing essential oil concentrations, compared with $R$. fasciculatum (Kapoor et al., 2002a). Experiments with other AMF species confirmed the occurrence of differential activity, as shown by data on the stimulation of root thymol derivative production, which was higher upon inoculation with Rhizoglomus clarum in Inula ensifolia roots (Zubek et al., 2010), and on the enhancement of shoot hypericin and pseudohypericin contents in Hypericum perforatum by Rhizoglomus intraradices (Zubek et al., 2012). Single species inocula showed different results also in artichoke, basil, lettuce, pepper and tomato (Table 1). When AMF species other than Glomeraceae were used as inoculum, large variations were found in the concentration of basil leaves essential oils: Gigaspora rosea largely increased the concentration of camphor and alfa-terpineol, while Gigaspora margarita highly decreased eucalyptol, linalool, eugenol content, and the total content of essential oils (Copetta et al., 2006).

As in agricultural ecosystems many different AMF co-occur in individual plants, it is important to assess plant performance in response to inoculation with multiple AMF species and/or isolates, either originating from natural communities or laboratory assemblages. Only few authors adopted such an approach, revealing the enhancement of some beneficial compounds by AMF mixtures, compared with single-isolate inoculation (Table 1). For example, total phenolic content (TPC) and antioxidant activity increased in leaf extracts and in flower heads of artichoke plants inoculated with a mixed inoculum, compared with single species inocula, both in microcosm and in the field, suggesting a synergistic effect and/or a functional complementarity between the AMF species (Ceccarelli et al., 2010). In another study the antioxidant activity expressed as the ferric reducing ability of plasma assay (FRAP) was enhanced in onion by a mixed commercial inoculum containing Claroideoglomus etunicatum, Rhizoglomus microaggregatum, R. intraradices, Claroideoglomus claroideum, F. mosseae, Funneliformis geosporus compared with a single species (R. intraradices) inoculum (Albrechtova et al., 2012). The use of mixed inocula vs. single species-inoculum showed in tomato contrasting results, depending on the active molecule involved in the modulation: the mixed AMF species F. mosseae BEG12 and $R$. irregulare BB-E increased $\beta$-carotene and total carotenoids levels with no effects on lycopene content, while an opposite result was obtained using the two species individually (Hart et al., 2015).

One possible mechanism by which AMF stimulate phytochemical production could be through enhanced nutrient uptake, especially P. Basil plants inoculated with Funneliformis caledonius and F. mosseae showed higher levels of rosmarinic acid (RA) in the shoots, compared with control plants of the same $\mathrm{P}$ status, suggesting that the increased RA concentrations were not exclusively the results of a better P nutrition (Toussaint et al., 2008). However, the effects of an improved $\mathrm{N}$ nutrition remain to be investigated, as the higher $\mathrm{N}$ assimilation in mycorrhizal plants could contribute to the synthesis of the aminoacids tyrosine and phenylalanine and to a higher production of phenylalanine ammonia-lyase, an enzyme involved in the production of RA (Petersen and Simmonds, 2003).

The parameters to be taken into account in order to select the best performing AMF isolates, species or communities, should refer not only to the content of the health-promoting secondary metabolites, but also to the levels of transcripts encoding the enzymes of the relevant pathways. Only two studies, related to the trascriptome of tomato (López-Ráez et al., 2010b) and grapevine (Balestrini et al., 2017) roots, used different AMF inocula. In tomato, $R$. intraradices was able to positively regulate a larger number of genes related to health bioactive molecules, compared 
with F. mosseae, whereas no differences in the modulation of genes by the two inoculants were observed in grapevine (Table 2). The ability of different AMF species and isolates to regulate genes related to beneficial phytochemicals should be further investigated by wide transcriptome studies, which could also provide insights into $\mathrm{P}$ and $\mathrm{N}$ nutrition-dependent effects. In particular, in the years to come metabolomic and transcriptomic analyses should be performed in experiments carried out under commercial production conditions-the normal way to grow plants used for human consumption-in order to avoid false positive responses.

\section{CONCLUSION AND FUTURE PERSPECTIVES}

The role played by AMF in the production of health-promoting phytochemicals by host plants has been widely investigated, using multimodal approaches. Although most of the studies showed increases in the levels of several phytochemicals in inoculated plants, some drawbacks hinder the implementation of these beneficial fungi for the production of high quality foods.

One of the main weakness concerning the data obtained so far entails the use of a low number of AMF species (about 24), generally the same ones utilized all over the world, that has limited the full exploitation of their wide physiological and genetic diversity. As the AMF species described so far are about 300, future studies should be performed utilizing the highest possible range of diverse AMF, not only at the species level, but also at the level of isolates and lineages within isolates (Chen et al., 2018; Savary et al., 2018), in order to select the best performing symbionts. Indeed, most of the physiological and functional characteristics of microorganisms, from bacteria to fungi, are properties of each individual strain. Unfortunately, the studies discussed so far often reported just the name of the AMF species utilized, and not always described the isolates, either with their number/name or with the name of the collection where they originated from.

Moreover, some of the studies analyzing the efficiency of laboratory-selected or commercial AMF strains when inoculated in the fields, found that their establishment and persistence were limited, due to the competition with well-adapted indigenous communities (Pellegrino et al., 2012; Loján et al., 2017). Such

\section{REFERENCES}

Adolfsson, L., Nziengui, H., Abreu, I. N., Šimura, J., Beebo, A., Herdean, A., et al. (2017). Enhanced secondary- and hormone metabolism in leaves of arbuscular mycorrhizal Medicago truncatula. Plant Physiol. 175, 392-411. doi: 10.1104/pp.16.01509

Alaux, P. L., César, V., Naveau, F., Cranenbrouck, S., and Declerck, S. (2018). Impact of Rhizophagus irregularis MUCL 41833 on disease symptoms caused by Phytophthora infestans in potato grown under field conditions. Crop Protect. 107, 26-33. doi: 10.1016/j.cropro.2018.01.003

Albrechtova, J., Latr, A., Nedorost, L., Pokluda, R., Posta, K., and Vosatka, M. (2012). Dual inoculation with mycorrhizal and saprotrophic fungi applicable in sustainable cultivation improves the yield and nutritive value of onion. Sci. World J. 2012:374091. doi: 10.1100/2012/374091 findings suggest that the selection of native AMF isolates could lead to more successful results. In order to scale up mesocosm experiments, as the success of AMF field inoculation is affected by many factors (Berruti et al., 2016), a more feasible and broadspectrum approach is represented by nursery inoculation of fruit trees or vegetable plant species before field transplant, which may allow early AMF establishment in roots and field persistence (Ceccarelli et al., 2010; Alaux et al., 2018).

Considering that in nature many different species and strains coexist in the same field, it is crucial to increase studies on the different AMF mixtures for detecting possible synergistic effects and functional complementarities among them, leading to a further selection of the best AMF combinations. Moreover, additional works should be performed on the effects of the combined inoculation of AMF with biostimulants and other beneficial microorganisms, such as plant growth promoting bacteria and fungi (i.e., Trichoderma spp.), whose metabolic activities could affect the outcome of the mixed inoculum (Lingua et al., 2013; Colla et al., 2015; Rouphael et al., 2015).

So far, RNA-Seq technology, together with a mechanistic approach, has been utilized for investigating the differential gene expression, mostly in root tissues. Further transcriptomic studies should explore the differential expression of genes involved in the biosynthesis of health-promoting plant compounds in edible tissues of mycorrhizal plants. Such a powerful technology should be applied in order to unravel the mechanisms encompassing the enhancement of health-promoting phytochemicals biosynthesis, as affected by the widest possible range of AMF. This will increase our knowledge on the specific role played by each strain, in order to utilize sound criteria for a finely tuned, targeted selection of the best performing symbionts, to be used as sustainable biotechnological tools for the production of safe and healthy plant foods.

\section{AUTHOR CONTRIBUTIONS}

All authors listed have made a substantial, direct and intellectual contribution to the work, and approved it for publication.

\section{FUNDING}

The authors gratefully acknowledge the financial support by the University of Pisa (Fondi di Ateneo) and C.N.R.

Avio, L., Sbrana, C., Giovannetti, M., and Frassinetti, S. (2017). Arbuscular mycorrhizal fungi affect total phenolics content and antioxidant activity in leaves of oak leaf lettuce varieties. Sci. Hortic. 224, 265-271. doi: 10.1016/j.scienta.2017.06.022

Balestrini, R., Salvioli, A., Dal Molin, A., Novero, M., Gabelli, G., Paparelli, E., et al. (2017). Impact of an arbuscular mycorrhizal fungus versus a mixed microbial inoculum on the transcriptome reprogramming of grapevine roots. Mycorrhiza 27, 417-430. doi: 10.1007/s00572-016-0754-8

Baslam, M., Garmendia, I., and Goicoechea, N. (2011). Arbuscular mycorrhizal fungi (AMF) improved growth and nutritional quality of greenhousegrown lettuce. J. Agric. Food Chem. 59, 5504-5515. doi: 10.1021/ jf200501c

Baslam, M., Garmendia, I., and Goicoechea, N. (2013). The arbuscular mycorrhizal symbiosis can overcome reductions in yield and nutritional quality in 
greenhouse-lettuces cultivated at inappropriate growing seasons. Sci. Hortic. 164, 145-154. doi: 10.1016/j.scienta.2013.09.021

Battini, F., Bernardi, R., Turrini, A., Agnolucci, M., and Giovannetti, M. (2016a). Rhizophagus intraradices or its associated bacteria affect gene expression of key enzymes involved in the rosmarinic acid biosynthetic pathway of basil. Mycorrhiza 26, 699-707. doi: 10.1007/s00572-016-0707-2

Battini, F., Turrini, A., Sgherri, C., Malorgio, F., and Quartacci, M. F. (2016b). Dual inoculation with AMF and associated bacteria improves nutraceutical value of sweet basil grown under commercial conditions. Agrochimica 60, 81-99. doi: $10.12871 / 0021857201623$

Berruti, A., Lumini, E., Balestrini, R., and Bianciotto, V. (2016). Arbuscular mycorrhizal fungi as natural biofertilizers: let's benefit from past successes. Front. Microbiol. 6:1559. doi: 10.3389/fmicb.2015.01559

Bhattacharya, U., Halder, B., Mukhopadhyay, S., and Giri, A. K. (2009). Role of oxidation-triggered activation of JNK and p38 MAPK in black tea polyphenols induced apoptotic death of A375 cells. Cancer Sci. 100, 1971-1978. doi: 10.1111/j.1349-7006.2009.01251.x

Bona, E., Cantamessa, S., Massa, N., Manassero, P., Marsano, F., Copetta, A., et al. (2017). Arbuscular mycorrhizal fungi and plant growth-promoting pseudomonads improve yield, quality and nutritional value of tomato: a field study. Mycorrhiza 27, 1-11. doi: 10.1007/s00572-016-0727-y

Bona, E., Lingua, G., Manassero, P., Cantamessa, S., Marsano, F., Todeschini, V., et al. (2015). AM fungi and PGP pseudomonads increase flowering, fruit production, and vitamin content in strawberry grown at low nitrogen and phosphorus levels. Mycorrhiza 25, 181-193. doi: 10.1007/s00572-014-0599-y

Bonanomi, A., Oetiker, J. H., Guggenheim, R., Boller, T., Wiemken, A., and Vögeli-Lange, R. (2001). Arbuscular mycorrhiza in mini-mycorrhizotrons: first contact of Medicago truncatula roots with Glomus intraradices induces chalcone synthase. New Phytol. 150, 573-582. doi: 10.1046/j.1469-8137.2001.00135.x

Burleigh, S. H., Cavagnaro, T., and Jakobsen, I. (2002). Functional diversity of arbuscular mycorrhizas extends to the expression of plant genes involved in P nutrition. J. Exp. Bot. 53, 1593-1601. doi: 10.1093/jxb/erf013

Butt, M. S., Sultan, M. T., Butt, M. S., and Iqbal, J. (2009). Garlic: nature's protection against physiological threats. Crit. Rev. Food Sci. Nutr. 49, 538-551. doi: $10.1080 / 10408390802145344$

Cameron, D. D., Neal, A. L., van Wees, S. C., and Ton, J. (2013). Mycorrhizainduced resistance: more than the sum of its parts? Trends Plant Sci. 18, 539-545. doi: 10.1016/j.tplants.2013.06.004

Campos-Soriano, L., García-Martínez, J., and San Segundo, B. (2012). The arbuscular mycorrhizal symbiosis promotes the systemic induction of regulatory defence-related genes in rice leaves and confers resistance to pathogen infection. Mol. Plant Pathol. 13, 579-592. doi: 10.1111/j.1364-3703.2011.00773.x

Canene-Adams, K., Campbell, J. K., Zaripheh, S., Jeffery, E. H., and Erdman, J. W. Jr. (2005). The tomato as a functional food. J. Nutr. 135, 1226-1230. doi: $10.1093 / \mathrm{jn} / 135.5 .1226$

Castellanos Morales, V., Villegas, J., Wendelin, S., Vierheilig, H., Eder, R., and Cárdenas Navarro, R. (2010). Root colonisation by the arbuscular mycorrhizal fungus Glomus intraradices alters the quality of strawberry fruits (Fragariax ananassa Duch.) at different nitrogen levels. J. Sci. Food Agric. 90, 1774-1782. doi: $10.1002 /$ jsfa. 3998

Castillo, C., Sotomayor, L., Ortiz, C., Leonelli, G., Borie, F., and Rubio, R. (2009). Effect of arbuscular mycorrhizal fungi on an ecological crop of chili peppers (Capsicum annuum L.). Chilean J. Agric. Res. 69, 79-87. doi: $10.4067 /$ S0718-58392009000100010

Cecatto, A. P., Ruiz, F. M., Calvete, E. O., Martínez, J., and Palencia, P. (2016). Mycorrhizal inoculation affects the phytochemical content in strawberry fruits. Acta Sci. Agron. 38, 227-237. doi: 10.4025/actasciagron.v38i2.27932

Ceccarelli, N., Curadi, M., Martelloni, L., Sbrana, C., Picciarelli, P., and Giovannetti, M. (2010). Mycorrhizal colonization impacts on phenolic content and antioxidant properties of artichoke leaves and flower heads two years after field transplant. Plant Soil 335, 311-323. doi: 10.1007/s11104-010-0417-z

Cervantes-Gámez, R. G., Bueno-Ibarra, M. A., Cruz-Mendívil, A., CalderónVázquez, C. L., Ramírez-Douriet, C. M., Maldonado-Mendoza, I. E., et al. (2016). Arbuscular mycorrhizal symbiosis-induced expression changes in Solanum lycopersicum leaves revealed by RNA-seq analysis. Plant Mol. Biol. Rep. 34, 89-102. doi: 10.1007/s11105-015-0903-9
Chaudhary, V., Kapoor, R., and Bhatnagar, A. K. (2008). Effectiveness of two arbuscular mycorrhizal fungi on concentrations of essential oil and artemisinin in three accessions of Artemisia annua L. Appl. Soil Ecol. 40, 174-181. doi: 10.1016/j.apsoil.2008.04.003

Chen, E. C., Morin, E., Beaudet, D., Noel, J., Yildirir, G., Ndikumana, S., et al. (2018). High intraspecific genome diversity in the model arbuscular mycorrhizal symbiont Rhizophagus irregularis. New Phytol. doi: 10.1111/nph.14989. [Epub ahead of print].

Chen, S., Jin, W., Liu, A., Zhang, S., Liu, D., Wang, F., et al. (2013). Arbuscular mycorrhizal fungi (AMF) increase growth and secondary metabolism in cucumber subjected to low temperature stress. Sci. Hortic. 160, 222-229. doi: 10.1016/j.scienta.2013.05.039

Colla, G., Rouphael, Y., Di Mattia, E., El-Nakhel, C., and Cardarelli, M. (2015). Co-inoculation of Glomus intraradices and Trichoderma atroviride acts as a biostimulant to promote growth, yield and nutrient uptake of vegetable crops. J. Sci. Food Agric. 95, 1706-1715. doi: 10.1002/jsfa.6875

Copetta, A., Bardi, L., Bertolone, E., and Berta, G. (2011). Fruit production and quality of tomato plants (Solanum lycopersicum L.) are affected by green compost and arbuscular mycorrhizal fungi. Plant Biosyst. 145, 106-115. doi: 10.1080/11263504.2010.539781

Copetta, A., Lingua, G., Bardi, L., Masoero, G., and Berta, G. (2007). Influence of arbuscular mycorrhizal fungi on growth and essential oil composition in Ocimum basilicum var. Genovese. Caryol. 60, 106-110. doi: 10.1080/00087114.2007.10589555

Copetta, A., Lingua, G., and Berta, G. (2006). Effects of three AM fungi on growth, distribution of glandular hairs, and essential oil production in Ocimum basilicum L. var. Genovese. Mycorrhiza 16, 485-494. doi: 10.1007/s00572-006-0065-6

Deguchi, Y., Banba, M., Shimoda, Y., Chechetka, S. A., Suzuri, R., Okusako, Y., et al. (2007). Transcriptome profiling of Lotus japonicus roots during arbuscular mycorrhiza development and comparison with that of nodulation. DNA Res. 14, 117-133. doi: 10.1093/dnares/dsm014

Dermatsev, V., Weingarten-Baror, C., Resnick, N., Gadkar, V., Wininger, S., Kolotilin, I., et al. (2010). Microarray analysis and functional tests suggest the involvement of expansins in the early stages of symbiosis of the arbuscular mycorrhizal fungus Glomus intraradices on tomato (Solanum lycopersicum). Mol. Plant Pathol. 11, 121-135. doi: 10.1111/j.1364-3703.2009. 00581.x

Dillard, C. J., and German, J. B. (2000). Phytochemicals: nutraceuticals and human health. J. Sci. Food Agric. 80, 1744-1756. doi: 10.1002/10970010(20000915)80:12<1744::AID-JSFA725>3.0.CO;2-W

Durán, P., Acuña, J. J., Armada, E., López-Castillo, O. M., Cornejo, P., Mora, M. L., et al. (2016). Inoculation with selenobacteria and arbuscular mycorrhizal fungi to enhance selenium content in lettuce plants and improve tolerance against drought stress. J. Soil Sci. Plant Nutr. 16, 211-225. doi: 10.4067/S0718-95162016005000017

Duthie, S. J. (2000). Plant polyphenols in cancer and heart disease: implications as nutritional antioxidants. Nut. Res. Rev. 13, 79-106. doi: $10.1079 / 095442200108729016$

Ezawa, T., and Saito, K. (2018). How do arbuscular mycorrhizal fungi handle phosphate? New insight into fine-tuning of phosphate metabolism. New Phytol. doi: 10.1111/nph.15187. [Epub ahead of print].

Farmer, M. J., Li, X., Feng, G., Zhao, B., Chatagnier, O., Gianinazzi, S., et al. (2007). Molecular monitoring of field-inoculated AMF to evaluate persistence in sweet potato crops in China. Appl. Soil Ecol. 35, 599-609. doi: 10.1016/j.apsoil.2006.09.012

Fester, T., and Hause, G. (2005). Accumulation of reactive oxygen species in arbuscular mycorrhizal roots. Mycorrhiza 15, 373-379. doi: 10.1007/s00572-005-0363-4

Fiorilli, V., Catoni, M., Miozzi, L., Novero, M., Accotto, G. P., and Lanfranco, L. (2009). Global and cell-type gene expression profiles in tomato plants colonized by an arbuscular mycorrhizal fungus. New Phytol. 184, 975-987. doi: 10.1111/j.1469-8137.2009.03031.x

Fiorilli, V., Vallino, M., Biselli, C., Faccio, A., Bagnaresi, P., and Bonfante, P. (2015). Host and non-host roots in rice: cellular and molecular approaches reveal differential responses to arbuscular mycorrhizal fungi. Front. Plant Sci. 6:636. doi: $10.3389 /$ fpls.2015.00636 
Gallou, A., Declerck, S., and Cranenbrouck, S. (2012). Transcriptional regulation of defence genes and involvement of the WRKY transcription factor in arbuscular mycorrhizal potato root colonization. Funct. Integr. Genomic. 12, 183-198. doi: 10.1007/s10142-011-0241-4

Gao, X., Zhao, S., Xu, Q. L., and Xiao, J. X. (2016). Transcriptome responses of grafted Citrus sinensis plants to inoculation with the arbuscular mycorrhizal fungus Glomus versiforme. Trees 30, 1073-1082. doi: 10.1007/s00468-015-1345-6

Garrido, J. M., Morcillo, R. J. L., Rodríguez, J. Á. M., and Bote, J. A. O. (2010). Variations in the mycorrhization characteristics in roots of wild-type and ABAdeficient tomato are accompanied by specific transcriptomic alterations. Mol. Plant-Microbe Interact. 23, 651-664. doi: 10.1094/MPMI-23-5-0651

Gerlach, N., Schmitz, J., Polatajko, A., Schlueter, U., Fahnenstich, H., Witt, S., et al. (2015). An integrated functional approach to dissect systemic responses in maize to arbuscular mycorrhizal symbiosis. Plant Cell Environ. 38, 1591-1612. doi: $10.1111 /$ pce. 12508

Gianinazzi, S., Gollotte, A., Binet, M. N., van Tuinen, D., Redecker, D., and Wipf, D. (2010). Agroecology: the key role of arbuscular mycorrhizas in ecosystem services. Mycorrhiza 20, 519-530. doi: 10.1007/s00572-010-0333-3

Giovannetti, M., and Avio, L. (2002). "Biotechnology of arbuscular mycorrhizas," in Applied Mycology and Biotechnology, Vol. 2 Agriculture and Food Production, eds G. G. Khachatourians and D. K. Arora (Amsterdam, NL: Elsevier), 275-310.

Giovannetti, M., Avio, L., Barale, R., Ceccarelli, N., Cristofani, R., Iezzi, A., et al. (2012). Nutraceutical value and safety of tomato fruits produced by mycorrhizal plants. Br. J. Nutr. 107, 242-251. doi: 10.1017/S000711451100290X

Giovannetti, M., Avio, L., and Sbrana, C. (2010). "Fungal spore germination and pre-symbiotic mycelial growth: physiological and genetic aspects" in Arbuscular Mycorrhizas: Physiology and Function, eds H. Koltai and Y. Kapulnik (Amsterdam, NL: Springer), 3-32.

Giovannetti, M., Fortuna, P., Citernesi, A. S., Morini, S., and Nuti, M. P. (2001). The occurrence of anastomosis formation and nuclear exchange in intact arbuscular mycorrhizal networks. New Phytol. 151, 717-724. doi: 10.1046/j.0028-646x.2001.00216.x

Goicoechea, N., Garmendia, I., Fabbrin, E. G., Bettoni, M. M., Palop, J. A., and Sanmartín, C. (2015). Selenium fertilization and mycorrhizal technology may interfere in enhancing bioactive compounds in edible tissues of lettuces. Sci. Hortic. 195, 163-172. doi: 10.1016/j.scienta.2015.09.007

Grunwald, U., Nyamsuren, O., Tamasloukht, M. B., Lapopin, L., Becker, A., Mann, P., et al. (2004). Identification of mycorrhiza-regulated genes with arbuscule development-related expression profile. Plant Mol. Biol. 55, 553-566. doi: 10.1007/s11103-004-1303-y

Güimil, S., Chang, H. S., Zhu, T., Sesma, A., Osbourn, A., Roux, et al. (2005). Comparative transcriptomics of rice reveals an ancient pattern of response to microbial colonization. Proc. Natl. Acad. Sci. 102, 8066-8070. doi: 10.1073/pnas.0502999102

Gutjahr, C., Sawers, R. J., Marti, G., Andrés-Hernández, L., Yang, S. Y., Casieri, L., et al. (2015). Transcriptome diversity among rice root types during asymbiosis and interaction with arbuscular mycorrhizal fungi. Proc. Natl. Acad. Sci. 112, 6754-6759. doi: 10.1073/pnas.1504142112

Handa, Y., Nishide, H., Takeda, N., Suzuki, Y., Kawaguchi, M., and Saito, K. (2015). RNA-seq transcriptional profiling of an arbuscular mycorrhiza provides insights into regulated and coordinated gene expression in Lotus japonicus and Rhizophagus irregularis. Plant Cell Physiol. 56, 1490-1511. doi: $10.1093 / \mathrm{pcp} / \mathrm{pcv} 071$

Harrison, M. J., and Dixon, R. A. (1993). Isoflavonoid accumulation and expression of defense gene transcripts during the establishment of vesicular-arbuscular mycorrhizal associations in roots of Medicago truncatula. Mol. Plant Microbe Interact. 6, 643-654. doi: 10.1094/MPMI-6-643

Harrison, M. J., and Dixon, R. A. (1994). Spatial patterns of expression of flavonoid/isoflavonoid pathway genes during interactions between roots of Medicago truncatula and the mycorrhizal fungus Glomus versiforme. Plant $J$. 6, 9-20. doi: 10.1046/j.1365-313X.1994.6010009.x

Hart, M., Ehret, D. L., Krumbein, A., Leung, C., Murch, S., Turi, C., et al. (2015). Inoculation with arbuscular mycorrhizal fungi improves the nutritional value of tomatoes. Mycorrhiza 25, 359-376. doi: 10.1007/s00572-014-0617-0

Herre, E. A., Mejia, L. C., Kyllo, D. A., Rojas, E., Maynard, Z., Butler, A., et al. (2007). Ecological implications of antipathogen effects of tropical fungal endophytes and mycorrhizae. Ecology 88, 550-558. doi: 10.1890/05-1606
Hohnjec, N., Vieweg, M. E., Pühler, A., Becker, A., and Küster, H. (2005). Overlaps in the transcriptional profiles of Medicago truncatula roots inoculated with two different Glomus fungi provide insights into the genetic program activated during arbuscular mycorrhiza. Plant Physiol. 137, 1283-1301. doi: 10.1104/pp.104.056572

Jakobsen, I., Abbott, L. K., and Robson, A. D. (1992). External hyphae of vesicular arbuscular mycorrhizal fungi associated with Trifolium subterraneum. 1. spread of hyphae and phosphorus inflow into roots. New Phytol. 120, 371-380. doi: 10.1111/j.1469-8137.1992.tb01077.x

Johnson, I. T. (2002). Glucosinolates: bioavailability and importance to health. Int. J. Vitam. Nutr. Res. 71, 26-31. doi: 10.1024/0300-9831.72.1.26

Jurkiewicz, A., Ryszka, P., Anielska, T., Waligorski, P., Białonska, D., Goralska, K., et al. (2010). Optimization of culture conditions of Arnica montana L: effects of mycorrhizal fungi and competing plants. Mycorrhiza 20, 293-306. doi: 10.1007/s00572-009-0280-z

Kapoor, R., Giri, B., and Mukerii, K. G. (2002a). Glomus macrocarpum: a potential bioinoculant to improve essential oil quality and concentration in Dill (Anethum graveolens L.) and Carum (Trachyspermum ammi (Linn.) Sprague). World J. Microbiol. Biotechnol. 18, 459-463. doi: 10.1023/A:1015522100497

Kapoor, R., Giri, B., and Mukerji, K. G. (2002b). Mycorrhization of coriander (Coriandrum sativum $\mathrm{L}$ ) to enhance the concentration and quality of essential oil. J. Sci. Food Agric. 82, 339-342. doi: 10.1002/jsfa.1039

Karagiannidis, N., Thomidis, T., Lazari, D., Panou- Filotheou, E., and Karagiannidou, C. (2011). Effect of three Greek arbuscular mycorrhizal fungi in improving the growth, nutrient concentration, and production of essential oils of oregano and mint plants. Sci. Hortic. 129, 329-334. doi: 10.1016/j.scienta.2011.03.043

Khaosaad, T., Krenn, L., Medjakovic, S., Ranner, A., Lössl, A., Nell, M., et al. (2008). Effect of mycorrhization on the isoflavone content and the phytoestrogen activity of red clover. Plant Physiol. 165, 1161-1167. doi: 10.1016/j.jplph.2007.08.015

Lambais, M. R., Rios-Ruiz, W. F., and Andrade, R. M. (2003). Antioxidant responses in bean (Phaseolus vulgaris) roots colonized by arbuscular mycorrhizal fungi. New Phytol. 160, 421-428. doi: 10.1046/j.1469-8137.2003.00881.x

Lazzè, M. C., Pizzala, R., Gutiérrez Pecharromán, F. J., Gatòn Garnica, P., Antolín Rodríguez, J. M., Fabris, N., et al. (2009). Grape waste extract obtained by supercritical fluid extraction contains bioactive antioxidant molecules and induces antiproliferative effects in human colon adenocarcinoma cells. J. Med. Food 12, 561-568. doi: 10.1089/jmf.2008.0150

Lee, J., and Scagel, C. F. (2009). Chicoric acid found in basil (Ocimum basilicum L.) leaves. Food Chem. 115, 650-656.

Lehmann, A., and Rillig, M. C. (2015). Arbuscular mycorrhizal contribution to copper, manganese and iron nutrient concentrations in crops-A meta-analysis. Soil Biol. Biochem. 81, 147-158. doi: 10.1016/j.soilbio.2014.11.013

Lingua, G., Bona, E., Manassero, P., Marsano, F., Todeschini, V., Cantamessa, S., et al. (2013). Arbuscular mycorrhizal fungi and plant growth-promoting pseudomonads increases anthocyanin concentration in strawberry fruits (Fragaria x ananassa var. Selva) in conditions of reduced fertilization. Int. J. Mol. Sci. 14, 16207-16225. doi: 10.3390/ijms140816207

Liu, J., Maldonado-Mendoza, I., Lopez-Meyer, M., Cheung, F., Town, C. D., and Harrison, M. J. (2007). Arbuscular mycorrhizal symbiosis is accompanied by local and systemic alterations in gene expression and an increase in disease resistance in the shoots. Plant J. 50, 529-544. doi: 10.1111/j.1365-313X.2007.03069.x

Lohse, S., Schliemann, W., Ammer, C., Kopka, J., Strack, D., and Fester, T. (2005). Organisation and metabolism of plastids and mitochondria in arbuscular mycorrhizal roots of Medicago truncatula. Plant Physiol. 139, 329-340. doi: 10.1104/pp.105.061457

Loján, P., Senés-Guerrero, C., Suárez, J. P., Kromann, P., Schüßler, A., and Declerck, S. (2017). Potato field-inoculation in Ecuador with Rhizophagus irregularis: no impact on growth performance and associated arbuscular mycorrhizal fungal communities. Symbiosis 73, 45-56. doi: 10.1007/s13199-016-0471-2

Lone, R., Shuab, R., Wani, K. A., Ganaie, M. A., Tiwari, A. K., and Koul, K. K. (2015). Mycorrhizal influence on metabolites, indigestible oligosaccharides, mineral nutrition and phytochemical constituents in onion (Allium cepa L.) plant. Sci. Hortic. 193, 55-61. doi: 10.1016/j.scienta.2015.06.032 
López-Ráez, J. A., Flors, V., Garcia, J. M., and Pozo, M. J. (2010a). AM symbiosis alters phenolic acid content in tomato roots. Plant Signal. Behav. 5, 1138-1140. doi: $10.4161 /$ psb.5.9.12659

López-Ráez, J. A., Verhage, A., Fernández, I., García, J. M., Azcón-Aguilar, C., Flors, V., et al. (2010b). Hormonal and transcriptional profiles highlight common and differential host responses to arbuscular mycorrhizal fungi and the regulation of the oxylipin pathway. J. Exp. Bot. 61, 2589-2601. doi: $10.1093 /$ jxb/erq089

Lund, E. (2003). Non-nutritive bioactive constituents of plants: dietary sources and health benefits of glucosinolates. Int. J. Vitam. Nutr. Res. 73, 135-143. doi: 10.1024/0300-9831.73.2.135

Ma, J., Sun, C., Bai, L., Dong, R., Yan, Y., Yu, X., et al. (2018). Transcriptome analysis of cucumber roots reveals key cold-resistance genes induced by AM fungi. Plant Mol. Biol. Rep. 36, 135-148. doi: 10.1007/s11105-018-1066-2

Massoumou, M., van Tuinen, D., Chatagnier, O., Arnould, C., Brechenmacher, L., Sanchez, L., et al. (2007). Medicago truncatula gene responses specific to arbuscular mycorrhiza interactions with different species and genera of Glomeromycota. Mycorrhiza 17, 223-234. doi: 10.1007/s00572-006-0099-9

Maurich, T., Iorio, M., Chimenti, D., and Turchi, G. (2006). Erybraedin C and bitucarpin A, two structurally related pterocarpans purified from Bituminaria bituminosa, induced apoptosis in human colon adenocarcinoma cell lines MMR-and p53-proficient and-deficient in a dose-, time-, and structure-dependent fashion. Chem-Biol. Interact. 159, 104-116. doi: 10.1016/j.cbi.2005.10.103

Mena-Violante, H. G., Ocampo-Jiménez, O., Dendooven, L., Martínez-Soto, G., González-Castañeda, J., Davies, F. T., et al. (2006). Arbuscular mycorrhizal fungi enhance fruit growth and quality of Chile ancho (Capsicum annuum L. cv San Luis) plants exposed to drought. Mycorrhiza 16, 261-267. doi: 10.1007/s00572-006-0043-Z

Mimica-Dukić, N., Bugarin, D., Grbovic, S., Mitic-Culafic, D., Vukovic-Gacic, B., Orcic, D., et al. (2010). Essential oil of Myrtus communis L. as a potential antioxidant and antimutagenic agents. Molecules 15, 2759-2770. doi: 10.3390/molecules 15042759

Mogren, L. M., Caspersen, S., Olsson, M. E., and Gertsson, U. E. (2007). Organically fertilized onions (Allium cepa L.): effects of the fertilizer placement method on quercetin content and soil nitrogen dynamics. J. Agric. Food Chem. 56, 361-367. doi: 10.1021/jf071813a

Mollavali, M., Perner, H., Rohn, S., Riehle, P., Hanschen, F. S., and Schwarz, D. (2018). Nitrogen form and mycorrhizal inoculation amount and timing affect flavonol biosynthesis in onion (Allium cepa L.). Mycorrhiza 28, 59-70. doi: 10.1007/s00572-017-0799-3

Njeru, E. M., Bocci, G., Avio, L., Sbrana, C., Turrini, A., Giovannetti, M., et al. (2017). Functional identity has a stronger effect than diversity on mycorrhizal symbiosis and productivity of field grown organic tomato. Eur. J. Agron. 86, 1-11. doi: 10.1016/j.eja.2017.02.007

Nzanza, B., Marais, D., and Soundy, P. (2012a). Response of tomato (Solanum lycopersicum L.) to nursery inoculation with Trichoderma harzianum and arbuscular mycorrhizal fungi under field conditions. Acta Agric. Scand. Sect. B 62, 209-215. doi: 10.1080/09064710.2011.598544

Nzanza, B., Marais, D., and Soundy, P. (2012b). Yield and nutrient content of tomato (Solanum lycopersicum L.) as influenced by Trichoderma harzianum and Glomus mosseae inoculation. Sci. Hortic. 144, 55-59. doi: 10.1016/j.scienta.2012.06.005

Ordookhani, K., Khavazi, K., Moezzi, A., and Rejali, F. (2010). Influence of PGPR and AMF on antioxidant activity, lycopene and potassium contents in tomato. Afr. J. Agric. Res. 5, 1108-1116. doi: 10.5897/AJAR09.183

Ososki, A. L., and Kennelly, E. J. (2003). Phytoestrogens: a review of the present state of research. Phytother. Res. 17, 845-869. doi: 10.1002/ptr.1364

Palermo, M., Colla, G., Barbieri, G., and Fogliano, V. (2013). Polyphenol metabolite profile of artichoke is modulated by agronomical practices and cooking method. J. Agric. Food Chem. 61, 7960-7968. doi: 10.1021/ jf401468s

Pandino, G., Lombardo, S., Antonino, L. M., Ruta, C., and Mauromicale, G. (2017). In vitro micropropagation and mycorrhizal treatment influences the polyphenols content profile of globe artichoke under field conditions. Food Res. Int. 99, 385-392. doi: 10.1016/j.foodres.2017.05.037

Peipp, H., Maier, W., Schmidt, J., Wray, V., and Strack, D. (1997). Arbuscular mycorrhizal fungus-induced changes in the accumulation of secondary compounds in barley roots. Phytochemistry 44, 581-587. doi: 10.1016/S0031-9422(96)00561-4

Pellegrino, E., Turrini, A., Gamper, H. A., Cafà, G., Bonari, E., Young, J. P. W., et al. (2012). Establishment, persistence and effectiveness of arbuscular mycorrhizal fungal inoculants in the field revealed using molecular genetic tracing and measurement of yield components. New Phytol. 194, 810-822. doi: 10.1111/j.1469-8137.2012.04090.x

Perner, H., Rohn, S., Driemel, G., Batt, N., Schwarz, D., Kroh, L. W., et al. (2008). Effect of nitrogen species supply and mycorrhizal colonization on organosulfur and phenolic compounds in onions. J. Agric. Food Chem. 56, 3538-3545. doi: $10.1021 / \mathrm{jf} 073337 \mathrm{u}$

Petersen, M., and Simmonds, M. S. (2003). Rosmarinic acid. Phytochemistry 62, 121-125. doi: 10.1016/S0031-9422(02)00513-7

Philippot, L., Raaijmakers, J. M., Lemanceau, P., and Van Der Putten, W. H. (2013). Going back to the roots: the microbial ecology of the rhizosphere. Nat. Rev. Microbiol. 11, 789-799. doi: 10.1038/nrmicro3109

Pistelli, L., Ulivieri, V., Giovanelli, S., Avio, L., Giovannetti, M., and Pistelli, L. (2017). Arbuscular mycorrhizal fungi alter the content and composition of secondary metabolites in Bituminaria bituminosa L. Plant Biol. 19, 926-933. doi: $10.1111 /$ plb. 12608

Ponce, M. A., Scervino, J. M., Erra-Balsells, R., Ocampo, J. A., and Godeas, A. M. (2004). Flavonoids from shoots and roots of Trifolium repens (white clover) grown in presence or absence of the arbuscular mycorrhizal fungus Glomus intraradices. Phytochemistry 65, 1925-1930. doi: 10.1016/j.phytochem.2004.06.005

Pozo, M. J., and Azcon-Aguilar, C. (2007). Unraveling mycorrhiza-induced resistance. Curr. Opin. Plant Biol. 10, 393-398. doi: 10.1016/j.pbi.2007.05.004

Rasouli-Sadaghiani, M., Hassani, A., Barin, M., Danesh, Y. R., and Sefidkon, F. (2010). Effects of AM fungi on growth, essential oil production and nutrients uptake in basil. J. Med. Plant Res. 4, 2222-2228. doi: 10.5897/ JMPR10.337

Rouphael, Y., Colla, G., Graziani, G., Ritieni, A., Cardarelli, M., and De Pascale, S. (2017). Phenolic composition, antioxidant activity and mineral profile in two seed-propagated artichoke cultivars as affected by microbial inoculants and planting time. Food Chem. 234, 10-19. doi: doi: 10.1016/j.foodchem.2017.04.175

Rouphael, Y., Franken, P., Schneider, C., Schwarz, D., Giovannetti, M., Agnolucci, M., et al. (2015). Arbuscular mycorrhizal fungi act as biostimulants in horticultural crops. Sci. Hortic. 196, 91-108. doi: 10.1016/j.scienta.2015.09.002

Sailo, G. L., and Bagyaraj, D. J. (2005). Influence of different AM-fungi on the growth, nutrition and forskolin content of Coleus forskohlii. Mycol. Res. 109, 795-798. doi: 10.1017/S0953756205002832

Salvioli, A., Zouari, I., Chalot, M., and Bonfante, P. (2012). The arbuscular mycorrhizal status has an impact on the transcriptome profile and amino acid composition of tomato fruit. BMC Plant Biol. 12:44. doi: 10.1186/1471-2229-12-44

Savary, R., Masclaux, F. G., Wyss, T., Droh, G., Corella, J. C., Machado, et al. (2018). A population genomics approach shows widespread geographical distribution of cryptic genomic forms of the symbiotic fungus Rhizophagus irregularis. ISME J. 12, 17-30. doi: 10.1038/ismej.2017.153

Sbrana, C., Avio, L., and Giovannetti, M. (2014). Beneficial mycorrhizal symbionts affecting the production of health-promoting phytochemicals. Electrophoresis 35, 1535-1546. doi: 10.1002/elps.201300568

Scagel, C. F., and Lee, J. (2012). Phenolic composition of basil plants is differentially altered by plant nutrient status and inoculation with mycorrhizal fungi. Hort. Sci. 47, 660-671.

Schaarschmidt, S., Gresshoff, P. M., and Hause, B. (2013). Analyzing the soybean transcriptome during autoregulation of mycorrhization identifies the transcription factors GmNF-YAla/b as positive regulators of arbuscular mycorrhization. Genome Biol. 14:R62. doi: 10.1186/gb-2013-14-6-r62

Schliemann, W., Ammer, C., and Strack, D. (2008). Metabolic profiling of mycorrhizal roots of Medicago truncatula. Phytochemistry 69, 112-146. doi: 10.1016/j.phytochem.2007.06.032

Schweiger, R., and Müller, C. (2015). Leaf metabolome in arbuscular mycorrhizal symbiosis. Curr. Opin. Plant Biol. 26, 120-126. doi: 10.1016/j.pbi.2015.06.009

Shu, B., Li, W., Liu, L., Wei, Y., and Shi, S. (2016). Transcriptomes of arbuscular mycorrhizal fungi and litchi host interaction after tree girdling. Front. Microbiol. 7:408. doi: 10.3389/fmicb.2016.00408 
Sikes, B. A., Kottenie, K., and Klironomos, J. N. (2009). Plant and fungal identity determines pathogen protection of plant roots by arbuscular mycorrhizas. $J$. Ecol. 97, 1274-1280. doi: 10.1111/j.1365-2745.2009.01557.x

Smith, S. E., and Read, D. J. (2008). Mycorrhizal Symbiosis. 3rd Edn. London: Academic Press.

Spatafora, J. W., Chang, Y., Benny, G. L., Lazarus, K., Smith, M. E., Berbee, M. L., et al. (2016). A phylum-level phylogenetic classification of zygomycete fungi based on genome-scale data. Mycologia 108, 1028-1046. doi: 10.3852/16-042

Subramanian, K. S., Santhanakrishnan, P., and Balasubramanian, P. (2006). Responses of field grown tomato plants to arbuscular mycorrhizal fungal colonization under varying intensities of drought stress. Sci. Hortic. 107, 245-253. doi: 10.1016/j.scienta.2005.07.006

Sugimura, Y., and Saito, K. (2017). Comparative transcriptome analysis between Solanum lycopersicum L. and Lotus japonicus L. during arbuscular mycorrhizal development. Soil Sci. Plant Nutr. 63, 127-136. doi: 10.1080/00380768.2017.1280378

Tang, L., Zirpoli, G. R., Jayaprakash, V., Reid, M. E., McCann, S. E., Nwogu, C. E., et al. (2010). Cruciferous vegetable intake is inversely associated with lung cancer risk among smokers: a case-control study. BMC Cancer 10:162. doi: 10.1186/1471-2407-10-162

Tavarini, S., Passera, B., Martini, A., Avio, L., Sbrana, C., Giovannetti, M., et al. (2018). Plant growth, steviol glycosides and nutrient uptake as affected by arbuscular mycorrhizal fungi and phosphorous fertilization in Stevia rebaudiana Bert. Ind. Crop. Prod. 111, 899-907. doi: 10.1016/j.indcrop.2017.10.05

Teiten, M. H., Gaascht, F., Dicato, M., and Diederich, M. (2013). Anticancer bioactivity of compounds from medicinal plants used in European medieval traditions. Biochem. Pharmacol. 86, 1239-1247. doi: 10.1016/j.bcp.2013.08.007

Tong, Y., Gabriel-Neumann, E., Ngwene, B., Krumbein, A., Baldermann, S., Schreiner, M., et al. (2013). Effects of single and mixed inoculation with two arbuscular mycorrhizal fungi in two different levels of phosphorus supply on $\beta$-carotene concentrations in sweet potato (Ipomoea batatas L.) tubers. Plant Soil 372, 361-374. doi: 10.1007/s11104-013-1708-y

Toussaint, J. P., Kraml, M., Nell, M., Smith, S. E., Smith, F. A., Steinkellner, S., et al. (2008). Effect of Glomus mosseae on concentrations of rosmarinic and caffeic acids and essential oil compounds in basil inoculated with Fusarium oxysporum f. sp. basilici. Plant Pathol. 57, 1109-1116. doi: 10.1111/j.1365-3059.2008.01895.x

Ulrichs, C., Fischer, G., Büttner, C., and Mewis, I. (2008). Comparison of lycopene, $\beta$-carotene and phenolic contents of tomato using conventional and ecological horticultural practices, and arbuscular mycorrhizal fungi (AMF). Agron. Colomb. 26, 40-46.
Vangelisti, A., Natali, L., Bernardi, R., Sbrana, C., Turrini, A., HassaniPak, K., et al. (2018). Transcriptome changes induced by arbuscular mycorrhizal fungi in sunflower (Helianthus annuus L.) roots. Sci. Rep. 8:4. doi: 10.1038/s41598-017-18445-0

Walter, M. H., Fester, T., and Strack, D. (2000). Arbuscular mycorrhizal fungi induce the non-mevalonate methylerythritol phosphate pathway of isoprenoid biosynthesis correlated with accumulation of the 'yellow pigment' and other apocarotenoids. Plant J. 21, 571-578. doi: 10.1046/j.1365-313x.2000.00708.x

Wang, S. Y., Lewers, K. S., Bowman, L., and Ding, M. (2007). Antioxidant activities and anticancer cell proliferation properties of wild strawberries. J. Am. Soc. Hortic. Sci. 132, 647-658.

Wipf, D., Mongelard, G., Van Tuinen, D., Gutierrez, L., and Casieri, L. (2014). Transcriptional responses of Medicago truncatula upon sulfur deficiency stress and arbuscular mycorrhizal symbiosis. Front. Plant Sci. 5:680. doi: $10.3389 /$ fpls.2014.00680

Zhang, X., Zhu, Y., Duan, W., Feng, C., and He, X. (2015). Allicin induces apoptosis of the MGC-803 human gastric carcinoma cell line through the p38 mitogen-activated protein kinase/caspase-3 signaling pathway. Mol. Med. Rep. 11, 2755-2760. doi: 10.3892/mmr.2014.3109

Zouari, I., Salvioli, A., Chialva, M., Novero, M., Miozzi, L., Tenore, G. C. et al. (2014). From root to fruit: RNA-Seq analysis shows that arbuscular mycorrhizal symbiosis may affect tomato fruit metabolism. BMC Genomics 15:221. doi: 10.1186/1471-2164-15-221

Zubek, S., Mielcarek, S., and Turnau, K. (2012). Hypericin and pseudohypericin concentrations of a valuable medicinal plant Hypericum perforatum L. are enhanced by arbuscular mycorrhizal fungi. Mycorrhiza 22, 149-156. doi: 10.1007/s00572-011-0391-1

Zubek, S., Stojakowska, A., Anielska, T., and Turnau, K. (2010). Arbuscular mycorrhizal fungi alter thymol derivative contents of Inula ensifolia L. Mycorrhiza 20, 497-504. doi: 10.1007/s00572-010-0306-6

Conflict of Interest Statement: The authors declare that the research was conducted in the absence of any commercial or financial relationships that could be construed as a potential conflict of interest.

Copyright (c) 2018 Avio, Turrini, Giovannetti and Sbrana. This is an open-access article distributed under the terms of the Creative Commons Attribution License (CC $B Y)$. The use, distribution or reproduction in other forums is permitted, provided the original author(s) and the copyright owner(s) are credited and that the original publication in this journal is cited, in accordance with accepted academic practice. No use, distribution or reproduction is permitted which does not comply with these terms. 